\title{
Innovation, Deregulation, and the Life Cycle of a Financial Service Industry
}




\section{WP/15/192}

New Text

\section{IMF Working Paper}

\section{Innovation, Deregulation, and the Life Cycle of a Financial Service Industry}

by Fumiko Hayashi, Bin Grace Li, and Zhu Wang

IMF Working Papers describe research in progress by the author(s) and are published to elicit comments and to encourage debate. The views expressed in IMF Working Papers are those of the author(s) and do not necessarily represent the views of the IMF, its Executive Board, or IMF management.
I $\mathrm{N}$
R A T I O N A L
$M O N E T A R Y$
F U N D 


\title{
IMF Working Paper
}

\author{
Research Department
}

\author{
Innovation, Deregulation, and the Life Cycle of a Financial Service Industry* \\ Prepared by Fumiko Hayashi, Bin Grace Li, and Zhu Wang \\ Authorized for distribution by Andrew Berg
}

August 2015

\begin{abstract}
IMF Working Papers describe research in progress by the author(s) and are published to elicit comments and to encourage debate. The views expressed in IMF Working Papers are those of the author(s) and do not necessarily represent the views of the IMF, its Executive Board, IMF management, the Federal Reserve Bank of Kansas City, and the Federal Reserve Bank of Richmond.
\end{abstract}

\begin{abstract}
This paper examines innovation, deregulation, and firm dynamics over the life cycle of the U.S. ATM and debit card industry. In doing so, we construct a dynamic equilibrium model to study how a major product innovation (introducing the new debit card function) interacted with banking deregulation drove the industry shakeout. Calibrating the model to a novel dataset on ATM network entry, exit, size, and product offerings shows that our theory fits the quantitative pattern of the industry well. The model also allows us to conduct counterfactual analyses to evaluate the respective roles that innovation and deregulation played in the industry evolution.
\end{abstract}

JEL Classification Numbers: L10; O30; G2

Keywords: Innovation; Deregulation; Industry Dynamics; Shakeout

Author's E-Mail Address: fumiko.hayashi@kc.frb.org; bli2@imf.org; zhu.wang@rich.frb.org

\footnotetext{
* We thank Ernie Berndt, Andreas Hornstein, Boyan Jovanovic, Sam Kortum, Yoonsoo Lee, Timothy Simcoe, Victor Stango, and participants at various seminars and conferences for helpful comments, and Joseph Johnson for excellent research assistance. The views expressed herein are solely those of the authors and do not necessarily reflect the views of the Federal Reserve Bank of Kansas City, the Federal Reserve Bank of Richmond, and the International Monetary Fund.
} 


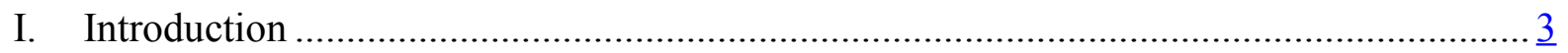

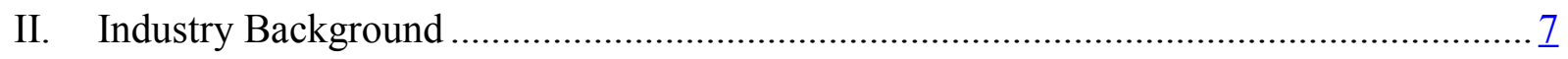

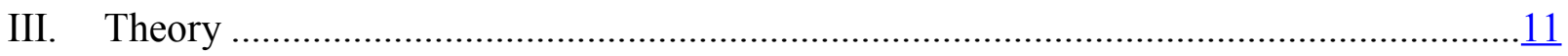

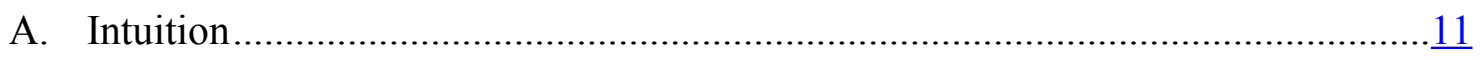

B. Model Basics ...............................................................................................

C. Emergence of ATM Networks .................................................................

D. Twin Shocks: Debit Innovation and Banking Deregulation ...............................15

E. Industry Dynamics: Characterization.............................................................

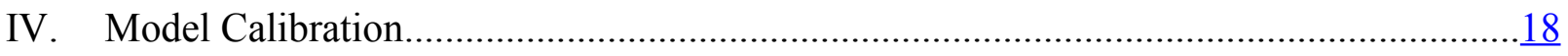

A. Parameterization ...................................................................................... 20

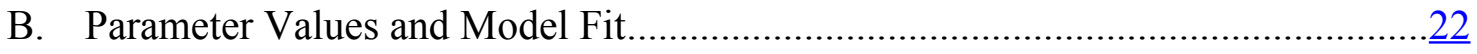

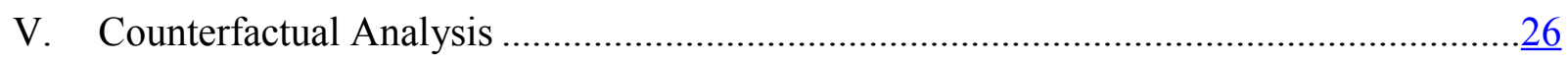

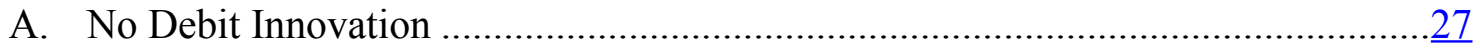

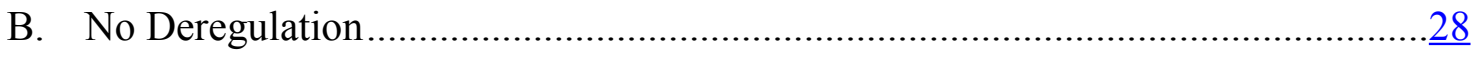

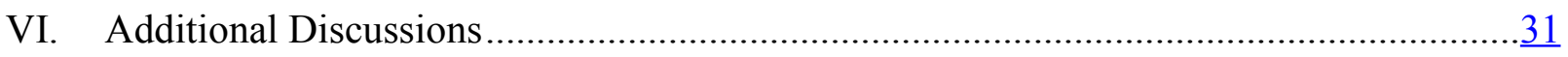

A. Anticipated Shocks ...............................................................................

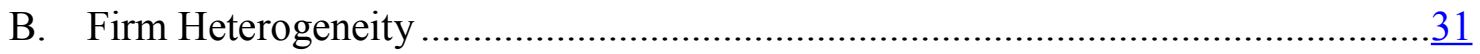

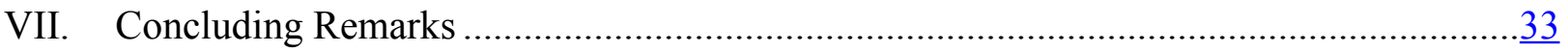

Appendix A: Timeline of the Industry Evolution .........................................................

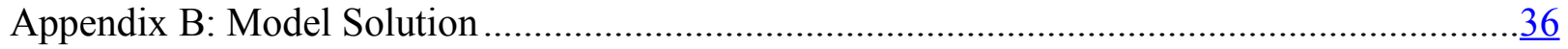

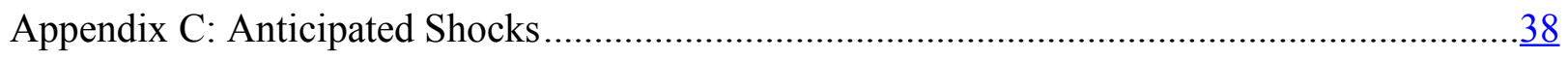

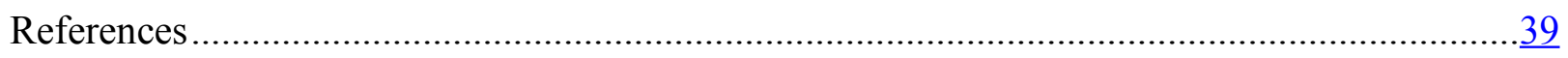

Figures

Figure 1. Shared ATM Networks and Transactions ................................................. 4

Figure 2. Debit and Banking Development ................................................................. $\underline{5}$

Figure 3. Evolution of Network Numbers .............................................................. 9

Figure 4. Industry Facts ................................................................................... 10

Figure 5. Model fit - Baseline Calibration ...............................................................24

Figure 6. Model Fit - Baseline Calibration (continued) ..............................................26

Figure 7. Counterfactual - No Innovation ................................................................... 27

Figure 8. Counterfactual - No Deregulation (Scenario 1) ….........................................29

Figure 9. counterfactual - No Deregulation (Scenario 2) ............................................

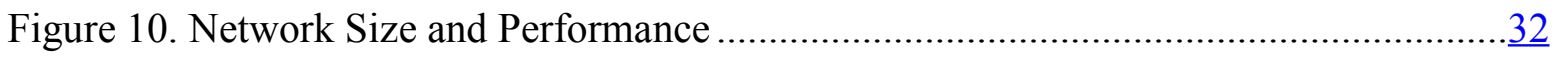

Table

Table 1. Parameter Values for Model Calibration ....................................................... 


\section{Introduction}

As new industries evolve from birth to maturity, it is typically observed that price falls, output rises, and firm numbers initially rise and later fall (Gort and Klepper, 1982; Klepper and Graddy, 1990; Agarwal and Gort, 1996). Eventually, only a small number of firms survive and the industry becomes concentrated. Many recent studies of industrial economics have been interested in explaining this profound life-cycle pattern of industry evolution, particularly the significant decline of firm numbers that takes place during periods of market expansion, termed as "shakeout."

Most existing theories, motivated by evidence from manufacturing industries, have focused on the role of technological innovations (e.g., Hopenhayn, 1994; Jovanovic and MacDonald, 1994; Klepper, 1996; Wang, 2008). They show that as an industry evolves, innovations tend to bring down production costs and increase the technology gap between firms. A shakeout then results when market demand turns inelastic or the inter-firm technology gap becomes sufficiently large. The literature has also debated on the relative importance of different types of innovations. A commonly expressed view is that product innovations tend to dominate at the early stage of the industry life cycle while process innovations take over later on, but the pattern can vary considerably across industries (Utterback and Suarez, 1993; Filson, 2001, 2002; Klepper and Simons, 2000, 2005; Cabral, 2012).

While this literature has greatly advanced our understanding of industry evolution, few studies have looked at non-manufacturing service industries, some of which may also experience shakeouts. ${ }^{1}$ One notable difference between manufacturing and services is that the latter are often under extensive government regulations. A strand of industrial organization literature has long been interested in the broad impact of deregulation on industry development. For instance, Winston (1998) provides a comprehensive survey of the literature that studies industry responses to deregulation in airlines, motor carriers, railroads, banking, and utilities. As those studies show, deregulation could have great impact on market structure, price, and output; and sometimes it may also cause

\footnotetext{
${ }^{1}$ For example, shakeouts have been documented in the wholesale drug industry (Fein, 1998), the internet industry (Demers and Lev, 2001), and the telecommunication industry (Barbarino and Jovanovic, 2007).
} 


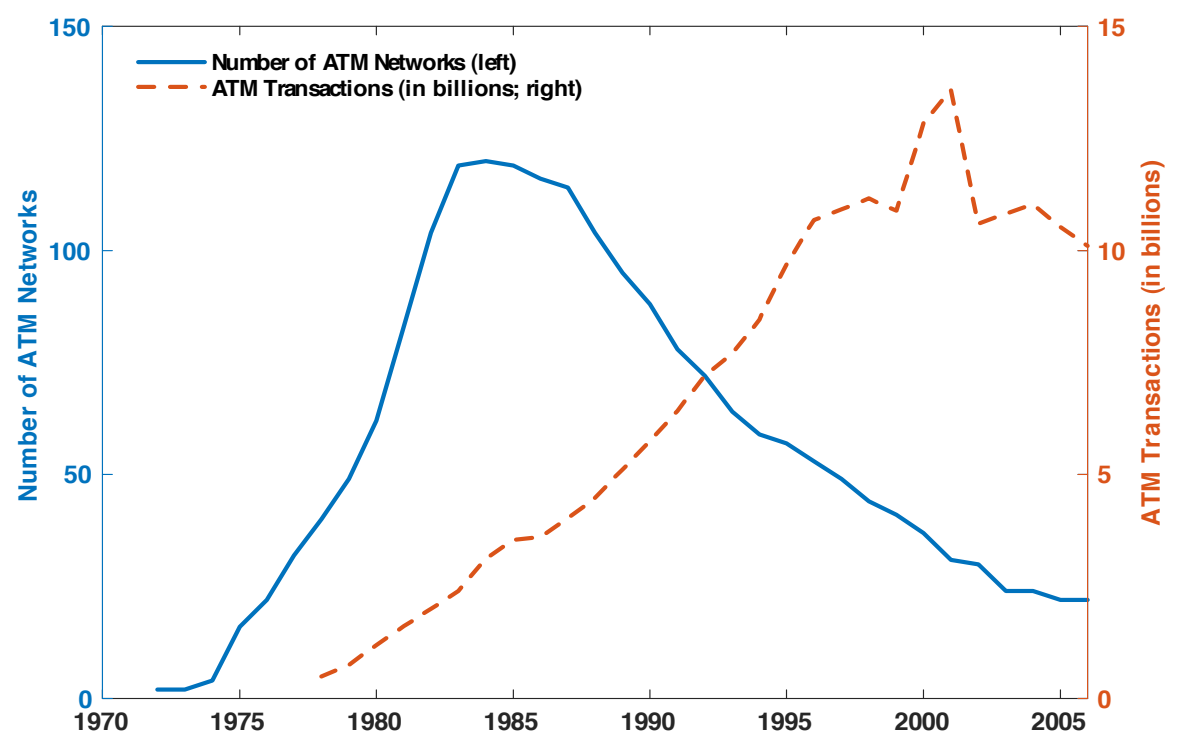

Figure 1: Shared ATM Networks and Transactions

substantial changes in the number of firms.

In this paper, we fill the gap in the literature by studying the life cycle of a financial service industry - the U.S. automated teller machine (ATM) and debit card industry, where both technological innovation and deregulation played important roles. In doing so, we construct a dynamic structural model and provide a quantitative assessment of the contribution of each of the factors.

The industry that we study started in the early 1970s. The firms we refer to are shared ATM networks, which deploy ATM machines and provide ATM services to cardholders from multiple financial institutions. As shown in Figure 1, the number of ATM networks grew rapidly to a peak in the mid-1980s but declined sharply afterward in spite of the continuing growth of ATM transaction volumes. ${ }^{2}$

We identify two major shocks at the outset of the shakeout. One was a product innovation - introducing the new debit card function in the mid-1980s. ${ }^{3}$ The debit innovation enhances the function of ATM cards, allowing cardholders to use them not

\footnotetext{
${ }^{2}$ Data source: Hayashi, Sullivan, and Weiner (2006). Note that the ATM transaction volumes reported after the 2000s no longer include certain subcategories used in the pre-2000 data, so the seeming decline of the ATM transactions in the 2000s is an artifact of changing data definition.

${ }^{3}$ The debit innovation can be traced back to the early 1980s, when the point of sale debit function was first tested in a large scale at some gas station chains (Hayashi, Sullivan, and Weiner, 2003). Based on our data source, 1984 was the first year that debit networks were reported.
} 

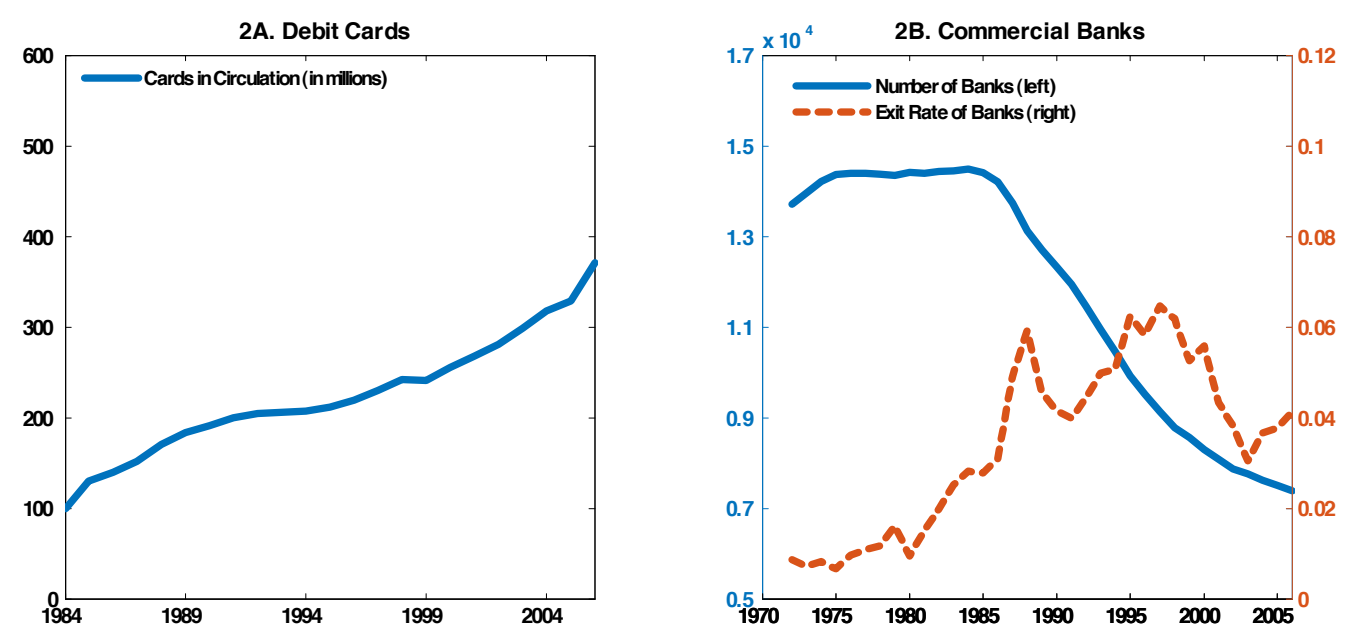

Figure 2: Debit and Banking Development

only at ATMs (i.e., as ATM cards), but also at retail locations to pay for goods and services (i.e., as debit cards). The synergies between the ATM and the debit services greatly increased the optimal size of networks (Felgran, 1985). This spurred a race of adopting the debit innovation among networks, especially in the early years. Over time, the joint ATM-debit technology became increasingly efficient and intensified the competition between networks that adopted the debit innovation and those that did not. Figure $2 \mathrm{~A}$ plots the increasing number of ATM cards that have enabled the debit function since the mid-1980s. ${ }^{4}$

Another major shock to the industry was the banking deregulation that started taking effect at about the same time. Figure 2B plots the total number of commercial banks in the United States as well as the annual bank exit rate from the early 1970s to the mid-2000s. ${ }^{5}$ It is striking to see that the U.S. banking industry had maintained an almost constant number of banks until the mid-1980s, with an annual exit rate as low as 1 percent. After that, the bank exit rate jumped to 6 percent and the total number of banks continued to decline. ${ }^{6}$ Because banks were the primary owners and

\footnotetext{
${ }^{4}$ Data source: Hayashi, Sullivan, and Weiner (2006).

${ }^{5}$ Data source: the FDIC.

${ }^{6}$ Bank branching restrictions date back to the Banking Act of 1933. In the mid-1970s, no state allowed out-of-state bank holding companies to buy in-state banks, and most states had intrastate branching restrictions. Starting in the late 1970s and early 1980s, most states began gradually relaxing restrictions on both statewide and interstate branching (Jayaratne and Strahan, 1997).
} 
customers of the ATM networks, the elevated exit of banks led to a higher exit risk of the latter. Meanwhile, the increased operational freedom of banks resulting from the deregulation also enhanced the optimal size of the ATM networks. In fact, as a part of the deregulation, an important legal development took place in the mid-1980s when the Supreme Court ruled in 1985 to uphold a federal appeals court's decision (i.e., the Marine Midland case in 1984) that national banks' use of shared ATM networks did not violate the federal branching restrictions. Following that, many states also started relaxing their restrictions on state banks' use of shared ATM networks. This removed one of the major obstacles that limited the geographic boundary of networks' operations. ${ }^{7}$

In this paper, we construct a dynamic equilibrium model to explain how the two major shocks interacted with each other and drove the shakeout in the ATM and debit card industry. Calibrating the model to a novel dataset on network entry, exit, size, and product offerings shows that our theory fits the quantitative pattern of the industry well. The model also allows us to conduct counterfactual analyses to evaluate the respective roles that innovation and deregulation played in the industry evolution. We find that both forces contributed to the shakeout, but their welfare effects may have been quite different. Particularly, whether deregulation enhances or undermines the industry performance depends on how much it facilitates technological progress relative to the additional disturbances it introduces to the industry.

Our model, à la Jovanovic and MacDonald (1994), studies technological shocks and shakeout in a competitive industry. However, our analysis offers several important novelties as motivated by the data. First, rather than focusing on a single process innovation in a homogenous good industry as in Jovanovic and MacDonald (1994), we study both product and process innovations in a heterogenous good industry. The data allows us to distinguish a major product innovation (i.e., introducing the new debit card function) from the subsequent process innovations (reflected by the continuing increase of network sizes), and we consider new and old card services as vertically differentiated goods competing in the same marketplace. Second, we endogenize firms' technology adoption decisions by considering their costs of adopting the debit innovation. Third, in addition to modelling technological innovations, we also incorporate the effect of

\footnotetext{
${ }^{7}$ Tibbals (1985) provides a detailed discussion on the court decisions on the Marine Midland case.
} 
banking deregulation in our analysis. Finally, our model calibration and counterfactual simulations provide a quantitative analysis that explains not only the industry-level outcomes (e.g., price, output, and firm numbers) as in Jovanovic and MacDonald (1994), but also firm-level observations, including entry, exit, size, and product offerings for different firm types.

The paper is organized as follows. Section II overviews the industry background and summarizes the key features of the industry evolution. Section III presents a dynamic model that characterizes the industry evolution. Section IV calibrates the model to a novel dataset on network entry, exit, size, and product offerings. Section V conducts counterfactual analyses to evaluate the roles that innovation and deregulation played in the industry shakeout. Section VI extends our analysis to consider anticipated shocks and heterogeneous firms. Section VII concludes.

\section{Industry Background}

The late 1960s marked the beginning of modern ATM services. The first ATMs were basically cash-dispensing machines. ${ }^{8}$ By the early 1970s, ATM technology had advanced to the system we know today. ATMs were developed to take deposits, transfer money between checking and savings accounts, provide cash advances from credit cards, and take payments. ATMs were also connected to computers, allowing real-time access to information about cardholder account balances and activity. By connecting ATMs of multiple financial institutions (banks) to a centralized system, shared networks began to emerge in the early 1970s (Felgran, 1984). ${ }^{9}$

Shared ATM networks generally take one of two forms of organization. First, a bank with a proprietary network can share with franchisees who purchase access to an entire system of terminals and computers. In this case, the proprietary network drives all the ATMs and does all the processing for the franchisees. Second, several banks can share a network through a joint venture. As in the cases of any joint venture, ownership

\footnotetext{
${ }^{8}$ In 1967, England's Barclays Bank installed the first cash dispenser. In 1968, Don Wetzel developed the first ATM in the United States using modern magnetic stripe access cards.

${ }^{9}$ In addition to the shared networks, some exclusive networks serving a single financial institution also existed in the early times. While our theory can equally apply to them, the data of exclusive networks are not available for analysis.
} 
is divided in some way depending on the arrangements made. In some cases, a third party such as a data processing company may retain an interest in the network.

A shared network allows cardholders to use any ATMs of participating banks in the network. This extends the geographic service area of banks and enhances consumer convenience. In the early years of the industry, most shared ATM networks were regional in scope. ${ }^{10}$ In return for providing the ATM service, networks charge fees to participating banks, which then pass the charges to their customers (McAndrews, 2003). ${ }^{11}$

The 1970s saw steady growth of shared ATM networks and the number of networks peaked around 120 in the mid-1980s. However, the industry went through a striking shakeout afterward. Half of the networks had exited by the mid-1990s and less than 30 networks survived to 2006 (Figure 1). As we discussed above, debit innovation and banking deregulation could be the two major shocks that drove the shakeout.

To study the industry evolution closely, we collect a novel dataset. The data are drawn from various issues of the EFT Data Book, which provides annual lists of regional ATM networks between 1984 and 2006. ${ }^{12}$ In total, we have 144 networks that existed at some point of time during the period. We then exclude 12 networks serving exclusively credit unions and/or savings and loan banks. ${ }^{13}$ For the remaining 132 networks in the sample, we also collect the number of cards in circulation and ATM transactions up to the year 2000. The dataset provides us great details on network entry, exit, size, and product offerings.

In the following figures, we summarize the key facts of the industry evolution, which will later serve as target moments for our model calibration. Figure 3 presents

\footnotetext{
${ }^{10}$ In some cases, a regional network might establish sharing agreements allowing its cardholders to access another network's ATMs under certain conditions and payments, but the network would maintain its separate identity and revenue.

${ }^{11}$ In reality, a bank either charges its customers explicit fees for card transactions (e.g., per-transaction fees or annual fees) or bundles the fees with other banking services.

${ }^{12}$ ATME3Debit News (formerly, Bank Network News) publishes the EFT Data Book annually (EFT stands for "Electronic Funds Transfer"). The dataset does not include national networks, such as Cirrus and Plus, because national networks used to play a different role than regional networks. They offered a "bridge" between regional networks. See Hayashi, Sullivan, and Weiner (2003) for details.

${ }^{13}$ Because our analysis considers the impact of commercial banking deregulation on ATM networks, it is necessary to exclude networks serving exclusively credit unions and/or savings and loan banks. Credit unions and savings and loan banks serve special groups of customers and were subject to different regulatory regimes, so the networks they used could have behaved differently than those serving commercial banks.
} 


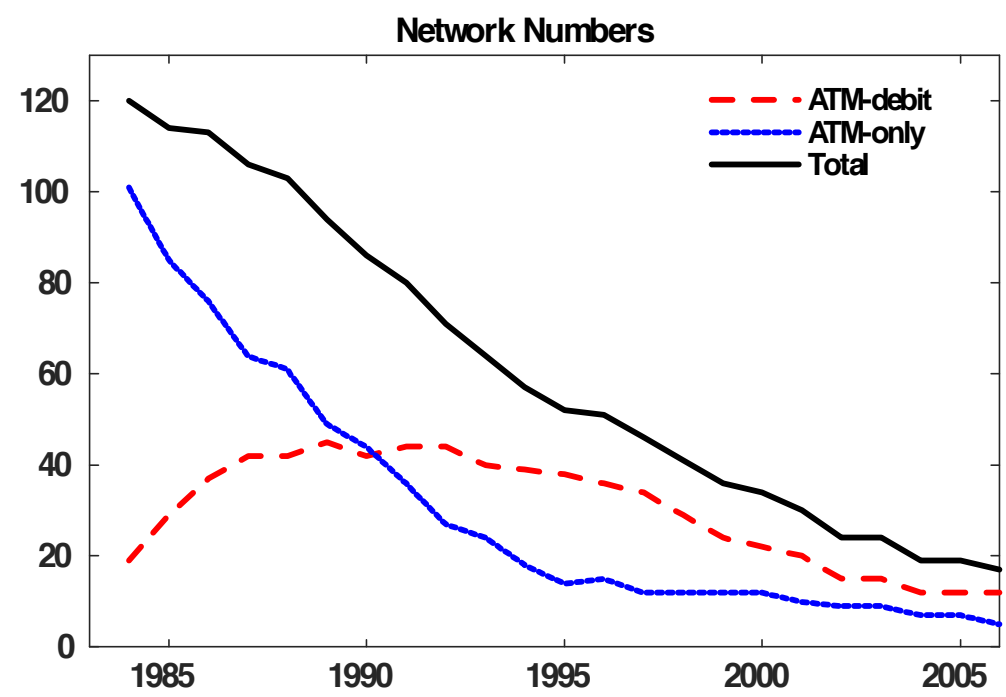

Figure 3: Evolution of Network Numbers

the network numbers in our sample from 1984-2006. While the total number of networks continued to decline in this period, the pattern was quite different between networks that adopted the debit innovation (denoted as "ATM-debit networks") and those that did not (denoted as "ATM-only networks"): The number of ATM-only networks declined monotonically, but the number of ATM-debit networks initially rose before later falling. Figures $4 \mathrm{~A}-4 \mathrm{~F}$ present several additional facts of the industry.

- Figure 4A shows that a short entry wave occurred on and after 1984 following the arrival of the debit innovation and banking deregulation, but the entry essentially stopped after 1987 (with only one exception in 1996).

- Figure 4B shows similar annual exit rates for different networks over time, with the ATM-only networks' exit rate being more volatile than the ATM-debit networks.

- Figure $4 \mathrm{C}$ shows the annual debit adoption rate by networks. The adoption rate stayed positive until 1994 but fell to zero afterward.

- Figure 4D plots the average network size by type (measured either by cards in circulation or ATM transaction volumes per network). The ATM-debit networks saw a dramatic size increase over time, which suggests rapid technological progress. In contrast, the size of ATM-only networks remained relatively stable. 
4A New Entrants

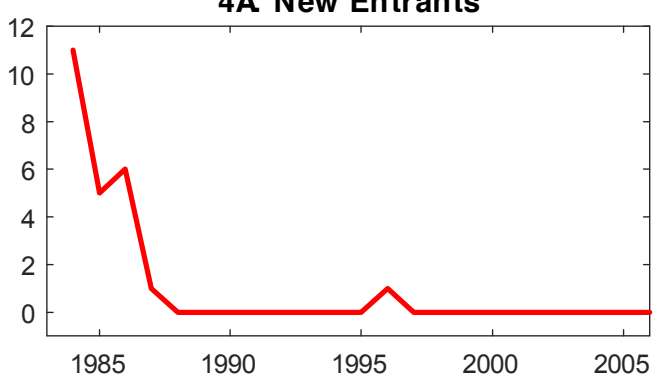

4C. Debit Adoption Rate

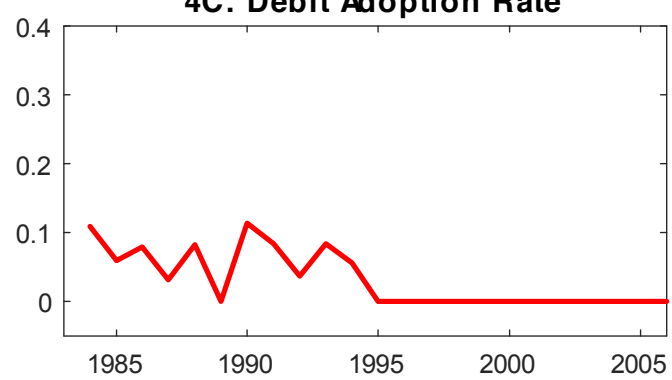

4E. Network Size Ratio

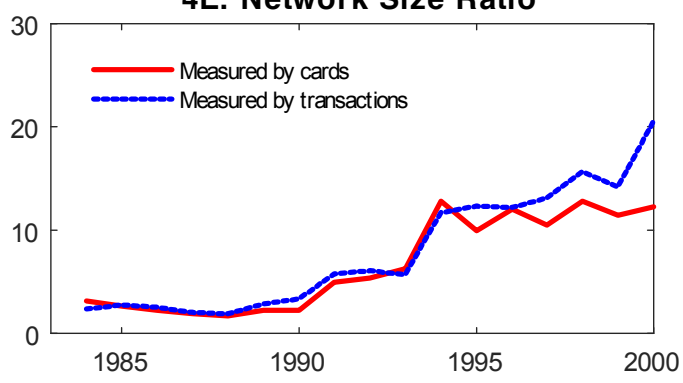

4B. Exit Rates

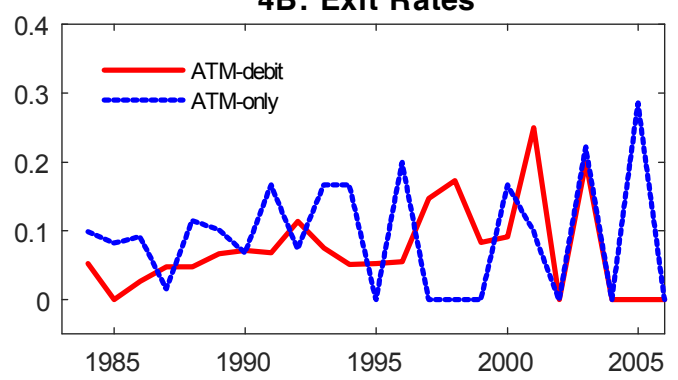

4D. Network Size

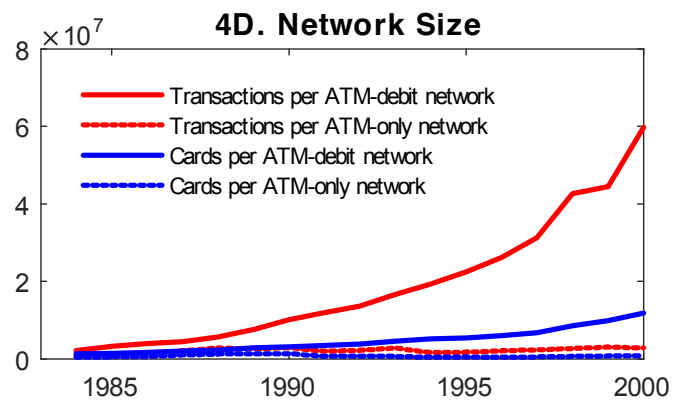

4F. Market Shares of Cards

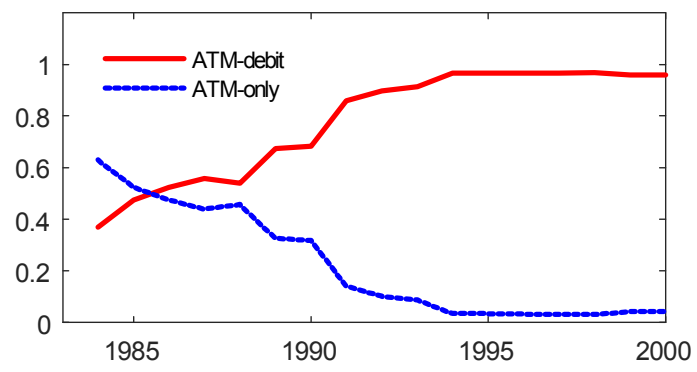

Figure 4: Industry Facts

- Figure $4 \mathrm{E}$ reports the size ratio between an average ATM-debit network and an average ATM-only network based on either cards in circulation or ATM transaction volumes. The two measures provide similar rising ratios over time. ${ }^{14}$

- Figure $4 \mathrm{~F}$ plots the total market shares for ATM-debit cards and ATM-only cards respectively. The share of ATM-debit cards increased sharply and exceeded 95 percent after the mid-1990s.

\footnotetext{
${ }^{14}$ In the data, some banks belong to multiple networks. This raises a concern of double counting when we measure networks' sizes based on their numbers of cards in circulation. To address this issue, we collect data on each network's ATM transactions. As shown in Figures 4D-4E, the two network size measures (cards in circulation vs. ATM transactions) deliver largely consistent patterns.
} 


\section{Theory}

In this section, we construct an industry evolution model in the context of ATM and debit card services, in which forward-looking networks make optimal decisions on entry, exit, firm size, and product offerings in a competitive market.

\section{A. Intuition}

Our theory presents the following industry evolution process (Appendix A provides an illustration of the timeline). At the very beginning of the industry, an "ATM-only" technology becomes available. A number of players pay a sunk cost to enter the new industry. The free entry condition determines the industry price, at which players are indifferent between entering or not. The industry then reaches a steady state with a constant number of networks, and entry and exit balance out in each period.

Then, at a point of time, two shocks arrive simultaneously. One is the debit innovation, which allows networks to offer a superior product, the ATM-debit card. The other is the banking deregulation, which increases the exogenous exit risk for networks but also allows networks, especially those that adopt the debit innovation, to increase their optimal sizes over time. In spite of the elevated exogenous exit risk, the increased profit opportunity attracts new entrants and induces existing networks to adopt the debit innovation. Adoption succeeds at a random rate and requires a fixed cost that rises over time. As more and more networks adopt the debit innovation, the prices of ATM-debit and ATM-only card services continue to fall. Because of the falling prices and rising adoption cost, entry is short lived and debit adoption eventually stops. After that, the technological progress of the ATM-debit networks continues to push down the industry prices, and at some point ATM-only networks choose to exit voluntarily. Along the industry evolution path, the shakeout arises as the joint result of the continuing exits and the endogenously determined lack of entry.

\section{B. Model Basics}

The model is cast in discrete time and infinite horizon. The environment is a competitive market for ATM and debit card services. Two generations of cards appear 
in the market subsequently. The first one is ATM-only cards, which cardholders can use exclusively at ATMs. The second generation is new ATM-debit cards, which cardholders can use not only at ATMs but also to pay at the point of sale.

On the supply side, card services are provided by networks. During the first generation of cards, there are ATM-only networks in the market, denoted as $a$. After the debit innovation arrives, ATM-debit networks emerge, denoted as $d$. Each network charges a fee $P^{i}$ per card according to the network type $i=\{a, d\}$, and incurs an initial fixed cost as well as variable costs to operate. ${ }^{15}$

On the demand side, consumers use card services provided by a network through their banks. There is a continuum of banks of mass one in the market. For simplicity, we assume each bank serves the same number of customers, which is normalized to be one. ${ }^{16}$ To provide card services to its customers, banks need to participate in a network and pay a fee $P^{i}$ per card to the network. When banks decide which network to join, they consider the quality of the card services provided by networks. Naturally, an ATMdebit card is more beneficial to the cardholder than an ATM-only card because of the additional debit function. Let $\omega^{i}$ denote the quality of card services, and we assume $\omega^{d}>\omega^{a}>0$.

For a bank, offering ATM or ATM-debit services raises its customers' willingness to pay for banking services and increases its total revenue by $\omega^{i} \theta$. Here $\theta$ is a bankspecific factor, which reflects its customers' preference for card services. We assume $\theta$ is distributed across banks according to a cumulative distribution function $G$. For each bank, the net revenue per card is expressed as

$$
\begin{gathered}
R\left(\theta ; \omega^{i}, P^{i}\right)=\omega^{i} \theta-P^{i}, \quad i=\{a, d\} . \\
\text { C. Emergence of ATM Networks }
\end{gathered}
$$

\section{Emergence of ATM Networks}

The market starts at time 0 when the ATM service becomes available. Potential network entrants, denoted by $\phi$, are of an infinite measure. Each period, a potential

\footnotetext{
${ }^{15}$ Note that assuming networks charge per transaction fees instead of per card fees would not affect our analysis since the number of card transactions is closely related to the number of cards.

${ }^{16}$ Note that bank size does not play a role in our analysis so this is an innocuous assumption.
} 
entrant may choose to enter the market or take an outside option for a payoff $\pi^{\phi} .{ }^{17} \mathrm{~A}$ new entrant pays an initial fixed cost $K$ to set up an ATM network, which takes one period to start operation. ${ }^{18}$ An existing network, however, may receive an exogenous exit shock each period with a probability $\gamma_{\text {pre }}$ and exit at the end of the period. Exiting does not incur additional costs, but the initial sunk cost cannot be recovered.

An ATM network $a$ earns a profit $\pi_{t}^{a}$ at time $t$, which depends on price $P_{t}^{a}$ and cost $C\left(q_{t}^{a}\right)$, i.e., $\pi_{t}^{a}=\max _{q_{t}^{a}}\left\{P_{t}^{a} q_{t}^{a}-C\left(q_{t}^{a}\right)\right\}$. Here, $C$ refers to a convex cost function, and $q_{t}^{a}$ is the quantity supplied by the network in terms of its number of cards in circulation. The convex cost reflects the fact that networks bear various operational and regulatory constraints, which give rise to numerous regional networks. Given that the cost function has the standard properties, we have $\partial \pi^{a} / \partial P^{a}>0$ and $\partial q^{a} / \partial P^{a}>0$.

For simplicity, we assume the chance of future innovations or market changes is too small to affect a network's decision. ${ }^{19}$ Hence, at each time $t \geq 0$, we have the following value functions:

$$
\begin{gathered}
U_{t}^{\phi}=\pi^{\phi}+\max \left\{\beta U_{t+1}^{\phi}, \beta U_{t+1}^{a}-K\right\} \\
U_{t}^{a}=\max \left\{\pi^{\phi}+\beta U_{t+1}^{\phi}, \pi_{t}^{a}+\gamma_{\text {pre }} \beta U_{t+1}^{\phi}+\left(1-\gamma_{\text {pre }}\right) \beta U_{t+1}^{a}\right\},
\end{gathered}
$$

where $U_{t}^{\phi}$ and $U_{t}^{a}$ are the value of a potential entrant $\phi$ and an ATM network $a$ at time $t$ respectively, and $\beta$ is the discount factor.

It can be shown that the industry has a steady state. Due to free entry, there exists a price $P^{a^{*}}$ at which potential entrants are indifferent between entering the industry and staying outside, so that Eq (1) implies that

$$
U^{\phi}=\frac{\pi^{\phi}}{1-\beta}=U^{a}-\frac{K}{\beta}
$$

Also, an incumbent network would strictly prefer staying in the industry because of the

\footnotetext{
${ }^{17}$ We can interpret $\pi^{\phi}$ as the foregone income of the network owner/manager for participating in the industry. For instance, it may equal the salary he or she could have earned in the banking or other comparable financial service sectors.

${ }^{18}$ This assumption follows the convention of the literature (e.g., Jovanovic and MacDonald, 1994), which was motivated by the empirical evidence of "time-to-build" found in many industries (Koeva, 2000).

${ }^{19}$ We will relax this assumption and consider anticipated shocks in Section VI.
} 
sunk cost paid. Accordingly, Eq (2) implies that

$$
U^{a}=\pi^{a}+\gamma_{p r e} \beta U^{\phi}+\left(1-\gamma_{p r e}\right) \beta U^{a} .
$$

Using (3) and (4), we can solve explicitly for $U^{a}$ :

$$
U^{a}=\frac{\pi^{a}-\gamma_{p r e} K}{1-\beta}
$$

Equations (3) and (5) then imply that

$$
\pi^{a}=\pi^{\phi}+\left(\gamma_{p r e}+\frac{1-\beta}{\beta}\right) K
$$

Because $\left(\gamma_{\text {pre }}+\frac{1-\beta}{\beta}\right) K>0$, Eq (6) suggests that $\pi^{a}\left(P^{a^{*}}\right)>\pi^{\phi}$.

On the demand side, banks choose whether to participate in an ATM network. At equilibrium, banks with a high value of $\theta\left(\theta \geq \frac{P^{a^{*}}}{\omega^{a}}\right)$ will do so because

$$
\omega^{a} \theta-P^{a^{*}} \geq 0 \Longrightarrow \theta \geq \frac{P^{a^{*}}}{\omega^{a}} .
$$

The total market demand for ATM cards is $1-G\left(\frac{P^{a^{*}}}{\omega^{a}}\right)$. In contrast, banks with a low value of $\theta\left(\theta<\frac{P^{a^{*}}}{\omega^{a}}\right)$ choose not to participate a network and they do not provide ATM services to their customers.

The market demand equals supply at the equilibrium. Hence,

$$
1-G\left(\frac{P^{a^{*}}}{\omega^{a}}\right)=N^{a} q^{a}\left(P^{a^{*}}\right),
$$

where $N^{a}$ is the number of ATM networks.

Equations (6) and (7) describe a simple industry equilibrium path: At time $0, N^{a}$ entrants choose to invest in the ATM technology and it takes one period to build the network. Thereafter, for any time $t \geq 1$, there are always $N^{a}$ networks operating in the market each having $q^{a}\left(P^{a^{*}}\right)$ cards in circulation, and the flows of network entry and exit balance out (i.e., at the end of each period, $\gamma_{p r e} N^{a}$ networks exit and get replaced by the same number of new entrants at the beginning of the next period). As a result, the 
total card supply $q^{a}\left(P^{a^{*}}\right) N^{a}$ equates the demand $1-G\left(\frac{P^{a^{*}}}{\omega^{a}}\right)$ in each period.

\section{Twin Shocks: Debit Innovation and Banking Deregulation}

At time $T$, the debit innovation and banking deregulation arrive as unexpected shocks. Because of the debit innovation, networks have a chance to offer a superior product, the ATM-debit card $d$. To implement the innovation, an ATM-only network needs to invest a fixed cost $I_{t}$ to upgrade its technology and recruit merchants to accept its cards, which involves uncertainties. We assume that the attempt may succeed with probability $\lambda$ or the network may fail and will have to try next period. ${ }^{20}$ Potential entrants may also enter, but they need to first build an ATM-only network before they can try adopting the debit innovation in subsequent periods. ${ }^{21}$

For an ATM-debit network, the profit $\pi_{t}^{d}$ depends on the price $P_{t}^{d}$ and $\operatorname{cost} g_{t} C\left(q_{t}^{d}\right)$, i.e., $\pi_{t}^{d}=\max _{q_{t}^{d}}\left\{P_{t}^{d} q_{t}^{d}-g_{t} C\left(q_{t}^{d}\right)\right\}$, where $C$ stands for the same convex cost function for ATM-only networks and $g_{t}$ is a cost-efficiency measure specific to ATM-debit. Because an ATM-debit card provides a better service than an ATM-only card (i.e., $\omega^{d}>\omega^{a}$ ), it charges a higher price at the equilibrium (i.e., $\left.P_{t}^{d}>P_{t}^{a}\right){ }^{22}$ We assume $\partial g_{t} / t<0$, which implies that an ATM-debit network enjoys an increasing cost efficiency over time (In contrast, we assume no technological progress for ATM-only networks given that they maintained an almost constant size in the sample period). ${ }^{23}$ We assume the cost of adopting debit innovation $I_{t}$ increases over time, which implies that as the technology gap between debit adopters and non-adopters widens, it becomes increasingly costly to

\footnotetext{
${ }^{20}$ The "failure" captures the uncertainties involved in adopting the debit function. Industry evidence has shown that it was not easy for networks to recruit merchants to accept debit cards due to the conflicts between merchants and banks over payment of transaction fees and the cost of POS terminals, and by the existence of multiple technical standards (Hayashi, Sullivan, and Weiner, 2003).

${ }^{21}$ The data show that almost all the new entrants entered as ATM-only networks after the debit innovation arrived.

${ }^{22}$ Note that if a low-quality card charges a higher price, it would have no demand.

${ }^{23}$ There are several sources of the increasing cost efficiency of ATM-debit networks. First, the synergies of providing ATM and debit services improve over time. For instance, providing debit services allows networks to learn about their customers' shopping patterns so that they can better allocate the ATM machines and services. Second, providing debit services allows networks to bring another user group, the merchants, on board. Over time, the increasing merchant sponsorship for debit services (e.g., merchant fees) helps offset the network costs. Third, the debit service itself has experienced rapid technological progress. Particularly, the operational cost and fraud rate has declined tremendously over time.
} 
adopt the innovation. ${ }^{24}$

Meanwhile, the banking deregulation results in an increased bank exit rate (as shown by Figure 2B). Because banks are networks' primary owners and customers, this introduces a higher exogenous exit risk to the networks, i.e., $\gamma>\gamma_{\text {pre }}$. Of course, banking deregulation may also allow networks, particularly the ATM-debit ones, to improve their cost efficiency. In other words, without the deregulation, $g_{t}$ would have been declining at a slower rate.

Upon the arrival of the debit innovation and banking deregulation, networks then reconsider their entry, exit, and product offerings. At each time $t \geq T$, we have the following value functions for networks by type:

$$
\begin{aligned}
V_{t}^{\phi}= & \pi^{\phi}+\max \left\{\beta V_{t+1}^{\phi}, \beta V_{t+1}^{a}-K\right\}, \\
V_{t}^{a}= & \max \left\{\pi^{\phi}+\beta V_{t+1}^{\phi}, \pi_{t}^{a}+\gamma \beta V_{t+1}^{\phi}+(1-\gamma) \max \left[\beta V_{t+1}^{a},\right.\right. \\
& \left.\left.\beta\left(\lambda V_{t+1}^{d}+(1-\lambda) V_{t+1}^{a}\right)-I_{t}\right]\right\}, \\
V_{t}^{d}= & \max \left\{\pi^{\phi}+\beta V_{t+1}^{\phi}, \pi_{t}^{d}+\gamma \beta V_{t+1}^{\phi}+(1-\gamma) \beta V_{t+1}^{d}\right\} .
\end{aligned}
$$

Equations (8)-(10) say the following: In (8), at each time $t \geq T$, a potential entrant $\phi$ may choose whether or not to enter as an ATM-only network (with the option of adopting the debit innovation in the subsequent periods). In (9), an incumbent ATMonly network $a$ has following options: At the beginning of each period, it may decide whether to voluntarily exit the industry. If it chooses to stay, it can earn a profit $\pi_{t}^{a}$, but there is a chance $\gamma$ that the network will receive an exogenous exit shock and exit at the end of the period. If it survives the exogenous shock, it will then plan for the next period by choosing to either stay as it is or pay an investment $I_{t}$ to adopt the debit innovation at a success rate $\lambda$. If it succeeds, it becomes an ATM-debit network; otherwise it stays as an ATM-only network. Equation (10) has the analogous interpretation for an ATM-debit network $d$.

\footnotetext{
${ }^{24}$ The increasing adoption cost $I_{t}$ helps explain why ATM-only networks eventually stopped adopting the debit innovation. It also reflects the increasing difficulties for a new debit network to recruit merchants and compete with the established networks in the debit arena.
} 


\section{E. Industry Dynamics: Characterization}

We denote the mass of the two types of active networks at time $t$ to be $n_{t} \equiv\left(n_{t}^{a}, n_{t}^{d}\right)$ and characterize the industry dynamics. Note that firms' entry and adoption decisions depend on the tradeoff between investment costs and future profits, so the industry evolution pattern could vary by the model parameter values. ${ }^{25}$ Our analysis will focus on the evolution patterns that are most empirically relevant, and we will later show our model calibration fits well with the data.

At time $T$, provided that the entry $\operatorname{cost} K$ can be justified by future profits, a number $N^{\phi}$ of new entrants enter as ATM-only networks. As suggested by Eq (8), a positive entry requires

$$
\beta V_{T+1}^{\phi}=\beta V_{T+1}^{a}-K \Longrightarrow V_{T+1}^{a}=\frac{\pi^{\phi}}{1-\beta}+\frac{K}{\beta}
$$

Meanwhile, all existing ATM-only networks (except the fraction $\gamma$ that receive an exogenous exit shock) attempt to adopt the debit innovation if that is profitable. We define the value of adopting debit to be $\Psi_{t} \equiv \beta\left(\lambda V_{t+1}^{d}+(1-\lambda) V_{t+1}^{a}\right)-I_{t}-\beta V_{t+1}^{a}$ as suggested by Eq (9). Therefore, networks will attempt to adopt if

$$
\Psi_{T}>0 \Longrightarrow V_{T+1}^{d}>V_{T+1}^{a}+\frac{I_{T}}{\beta \lambda} .
$$

Since it takes one period for the adoption to take effect and all exogenous exits occur at the end of the period, there is no change in price and output in this period.

At time $T+1, N^{\phi}$ new ATM-only networks appear in the market. There are also $(1-\gamma) N^{a}$ incumbent ATM-only networks that survive the exogenous exit shock last period, of which a fraction $\lambda$ succeeds in adopting the debit innovation this period. From then on, as long as the value of $\Psi_{t}$ stays positive (i.e., $V_{t+1}^{d}>V_{t+1}^{a}+\frac{I t}{\beta \lambda}$ ), incumbent ATMonly networks will continue to try adopting the debit innovation. However, provided that the adoption cost $I_{t}$ increases sufficiently fast over time, $\Psi_{t}$ decreases in $t$.

\footnotetext{
${ }^{25}$ For example, paths with no entry are possible (e.g., when the technological progress associated with the debit innovation is too slow or the investment costs are too high). In the counterfactual analyses in Section V, we show how the number of entrants is affected by the exit risk and by the rate of technological progress.
} 
Meanwhile, despite a fraction $\gamma$ of networks exogenously exiting every period, we assume that the increasing supply of ATM-debit cards through network conversion (i.e., an increasing $n_{t}^{d}$ ) and technological progress (i.e., a decreasing $g_{t}$ ) is large enough to continue pushing down the prices $P_{t}^{a}$ and $P_{t}^{d}$, so an increasing number of consumers use ATM and/or debit services. Also, as $\Psi_{t}$ and $P_{t}^{a}$ falls over time, this drives down the value of $V_{t}^{a}$ as suggested by $\mathrm{Eq}(9)$. As a result, there would be no further entry from outside the industry after time $T+1$.

At time $T^{\prime}$, the value of adopting debit $\Psi_{t}$ falls below zero so that ATM-only networks no longer find it profitable to try adopting the debit innovation. Hence, for the time period $T+1 \leq t \leq T^{\prime}-1$, the number of each type of networks is given by the following equations

$$
\begin{gathered}
n_{t}^{a}=[(1-\gamma)(1-\lambda)]^{t-T-1}\left[N^{\phi}+N^{a}(1-\gamma)(1-\lambda)\right], \\
n_{t}^{d}=(1-\gamma)^{t-T-1}\left[N^{\phi}+N^{a}(1-\gamma)\right]-n_{t}^{a} .
\end{gathered}
$$

However, from time $T^{\prime}$ and afterward, the supply of ATM-debit cards continues to increase due to technological progress (i.e., a decreasing $g_{t}$ ) and drives down the card prices $P_{t}^{a}$ and $P_{t}^{d}$. Eventually, ATM-only networks may choose to exit voluntarily, but the exit pattern could vary by parameter values.

In one scenario, the price of ATM-only cards reaches a critical value $\bar{P}^{a}$ at time $T^{\prime \prime}$, for which $\pi^{a}\left(\bar{P}^{a}\right)=\pi^{\phi}$, so some ATM-only networks become indifferent between staying and exiting the market. Note that for $T^{\prime} \leq t \leq T^{\prime \prime}-1$, the number of each type of networks is

$$
\begin{aligned}
& n_{t}^{a}=(1-\gamma)^{t-T^{\prime}+1} n_{T^{\prime}-1}^{a}, \\
& n_{t}^{d}=(1-\gamma)^{t-T^{\prime}+1} n_{T^{\prime}-1}^{d},
\end{aligned}
$$

where $n_{T^{\prime}-1}^{a}$ and $n_{T^{\prime}-1}^{d}$ are given by Eqs (13) and (14). Meanwhile, the market demand meets the supply for the ATM-debit cards:

$$
1-G\left(\frac{P_{t}^{d}-P_{t}^{a}}{\omega^{d}-\omega^{a}}\right)=n_{t}^{d} q_{t}^{d}\left(P_{t}^{d}\right),
$$


and for the ATM-only cards:

$$
G\left(\frac{P_{t}^{d}-P_{t}^{a}}{\omega^{d}-\omega^{a}}\right)-G\left(\frac{P_{t}^{a}}{\omega^{a}}\right)=n_{t}^{a} q^{a}\left(P_{t}^{a}\right) .
$$

From time $T^{\prime \prime}$ and afterward, some (but not all) ATM-only networks exit voluntarily. As long as there are voluntary exits of ATM-only networks, the industry equilibrium requires that $P_{t}^{a}=\bar{P}^{a}$ and

$$
\begin{gathered}
1-G\left(\frac{P_{t}^{d}-\bar{P}^{a}}{\omega^{d}-\omega^{a}}\right)=n_{t}^{d} q_{t}^{d}\left(P_{t}^{d}\right), \\
1-G\left(\frac{\bar{P}^{a}}{\omega^{a}}\right)=n_{t}^{d} q_{t}^{d}\left(P_{t}^{d}\right)+n_{t}^{a} q^{a}\left(\bar{P}^{a}\right),
\end{gathered}
$$

where

$$
n_{t}^{d}=(1-\gamma)^{t-T^{\prime \prime}+1} n_{T^{\prime \prime}-1}^{d} .
$$

This yields that

$$
n_{t}^{a}=\frac{1-G\left(\frac{\bar{P}^{a}}{\omega^{a}}\right)-n_{t}^{d} q_{t}^{d}\left(P_{t}^{d}\right)}{q^{a}\left(\bar{P}^{a}\right)} .
$$

Hence, the number of ATM-only networks that voluntarily exit in each period is

$$
x_{t}^{a}=(1-\gamma) n_{t-1}^{a}-n_{t}^{a} .
$$

However, there could exist other scenarios. Consider that, for certain parameter values, we obtain $n_{t}^{a}<0$ from Eq (21) at time $T^{\prime \prime}$. In this case, all the ATM-only networks have to exit at $T^{\prime \prime}$, and the only cards remaining in circulation would be the ATM-debit ones. If the price $P_{T^{\prime \prime}}^{d}$, determined by

$$
1-G\left(\frac{P_{T^{\prime \prime}}^{d}}{\omega^{d}}\right)=n_{T^{\prime \prime}}^{d} q_{T^{\prime \prime}}^{d}\left(P_{T^{\prime \prime}}^{d}\right),
$$

yields a profit $\pi_{T^{\prime \prime}}^{d}\left(P_{T^{\prime \prime}}^{d}\right)>\pi^{\phi}$, then no ATM-debit network would exit voluntarily. Thereafter, while a fraction $\gamma$ of remaining ATM-debit networks exit each period due to the exogenous exit shock, no ATM-debit network would want to voluntarily exit if the value of stay is greater than the outside option. In fact, we can show that if the card demand 
implied by the distribution $G$ is price elastic, an improving technology (due to the decreasing $g_{t}$ ) together with the declining network numbers (due to the exogenous exit rate $\gamma$ ) will always raise network profit $\pi_{t}^{d}$. Therefore, $\pi_{t}^{d}>\pi^{\phi}$ holds for any $t>T^{\prime \prime}$, so no ATM-debit network will voluntarily exit.

More generally, if for certain parameter values we obtain $n_{t}^{a}<0$ from Eq (21) for any time $t>T^{\prime \prime}$, a similar analysis applies.

\section{Model Calibration}

Our theory characterizes the process of how the twin shocks, debit innovation and banking deregulation, drove the shakeout in the ATM and debit card industry. In this section, we calibrate the model to the dataset that we introduced in Section II, and show that our theory fits the quantitative pattern of the industry well.

\section{A. Parameterization}

For the model calibration, we first specify the convex cost function for an ATM-only network to be

$$
C\left(q_{t}^{a}\right)=c_{0}\left(q_{t}^{a}\right)^{c_{1}} \quad \text { where } c_{0}>0 \text { and } c_{1}>1
$$

The corresponding profit function is

$$
\pi_{t}^{a}\left(P_{t}^{a}\right)=\left(c_{1}-1\right) c_{1}^{\frac{c_{1}}{1-c_{1}}} c_{0}^{\frac{1}{1-c_{1}}}\left(P_{t}^{a}\right)^{\frac{c_{1}}{c_{1}-1}}
$$

and the output function is

$$
q_{t}^{a}\left(P_{t}^{a}\right)=\left(\frac{P_{t}^{a}}{c_{0} c_{1}}\right)^{\frac{1}{c_{1}-1}}
$$

Similarly, we specify the cost function for an ATM-debit network to be $c_{0}\left(q_{t}^{d}\right)^{c_{1}} g_{t}$, so the profit function is

$$
\pi_{t}^{d}\left(P_{t}^{d}\right)=\left(g_{t}\right)^{\frac{1}{1-c_{1}}}\left(c_{1}-1\right) c_{1}^{\frac{c_{1}}{1-c_{1}}} c_{0}^{\frac{1}{1-c_{1}}}\left(P_{t}^{d}\right)^{\frac{c_{1}}{c_{1}-1}}
$$


and the output function is

$$
q_{t}^{d}\left(P_{t}^{d}\right)=\left(g_{t}\right)^{\frac{1}{1-c_{1}}}\left(\frac{P_{t}^{d}}{c_{0} c_{1}}\right)^{\frac{1}{c_{1}-1}}
$$

On the demand side, we assume that the heterogeneity of banks $\theta$ follows a Pareto distribution

$$
G(\theta)=1-d_{0} \theta^{-d_{1}} \quad \text { where } d_{0}>0 \text { and } d_{1}>1
$$

Accordingly, when there is only one type of card in the market (e.g., before debit function is introduced or after the ATM-only networks have all exited), the demand for the card services has a constant elasticity

$$
Q_{t}^{i}=d_{0}\left(\frac{P_{t}^{i}}{\omega^{i}}\right)^{-d_{1}}, i=\{a, d\}
$$

Otherwise, when there are two types of cards in the market, the demand for ATM-debit cards is

$$
Q_{t}^{d}=d_{0}\left(\frac{P_{t}^{d}-P_{t}^{a}}{\omega^{d}-\omega^{a}}\right)^{-d_{1}}
$$

and the demand for ATM-only cards is

$$
Q_{t}^{a}=d_{0}\left(\frac{P_{t}^{a}}{\omega^{a}}\right)^{-d_{1}}-d_{0}\left(\frac{P_{t}^{d}-P_{t}^{a}}{\omega^{d}-\omega^{a}}\right)^{-d_{1}}
$$

Since ATM-debit and ATM-only cards are substitute goods, their demands depend on each other's prices.

Given the above parameterization, the time path for the model industry is obtained as follows. Before the twin shocks, the industry steady state $\left(P^{a^{*}}, N^{a}\right)$ is determined by two equations:

$$
N^{a}\left(\frac{P^{a^{*}}}{c_{0} c_{1}}\right)^{\frac{1}{c_{1}-1}}=d_{0}\left(\frac{P^{a^{*}}}{\omega^{a}}\right)^{-d_{1}}
$$

and

$$
\pi^{\phi}=\left(c_{1}-1\right) c_{1}^{\frac{c_{1}}{1-c_{1}}} c_{0}^{\frac{1}{1-c_{1}}}\left(P^{a^{*}}\right)^{\frac{c_{1}}{c_{1-1}}}-\left(\gamma_{\text {pre }}+\frac{1-\beta}{\beta}\right) K
$$

where the first one requires that supply equates demand, and the second one reflects the 
free entry of networks.

After the twin shocks arrive, players then reconsider their entry, exit, and product decisions by taking into account the debit adoption cost

$$
I_{t}=I_{0}\left(1+I_{1}\right)^{t-T}, \quad \text { where } I_{0}>0,1>I_{1}>0
$$

the debit adoption success rate $\lambda$, the debit technological progress

$$
g_{t}=g_{0}\left(1-g_{1}\right)^{t-T}, \quad \text { where } 0<g_{0}, 0<g_{1}<1
$$

and the increased exogenous exit rate $\gamma>\gamma_{p r e}$. To ensure a stationary equilibrium, we assume that $g_{t}$ and $I_{t}$ will reach constant levels and $\gamma$ will go to zero after $t$ gets sufficiently large. ${ }^{26}$

The model equilibrium can be solved using backward induction to pin down the number of entrants $N^{\phi}$ at time $T$, the final time of debit adoption $T^{\prime}$, the time $T^{\prime \prime}$ when the voluntary exit starts, and the time paths of other endogenous variables, including prices $\left(P_{t}^{a}, P_{t}^{d}\right)$, outputs per network $\left(q_{t}^{a}, q_{t}^{d}\right)$, profits $\left(\pi_{t}^{a}, \pi_{t}^{d}\right)$, network numbers $\left(n_{t}^{a}, n_{t}^{d}\right)$, value functions $\left(V_{t}^{a}, V_{t}^{d}\right)$, and voluntary exits $x_{t}^{a}$. Appendix B provides technical details of the numerical solution to the model.

\section{B. Parameter Values and Model Fit}

Given the above functional forms, we choose parameter values to fit the data. Based on our data source, we consider that the twin shocks arrived in 1983 and debit technology was first used in production in 1984. We then calibrate the model to match the following data moments. Parameter values used for the calibration are reported in Table 1.

- Pre-shock steady state in 1983: (1) number of networks, and (2) number of cards in circulation per network. ${ }^{27}$

\footnotetext{
${ }^{26}$ In our numerical exercises, we assume that $g_{t}$ and $I_{t}$ will reach constant levels after 150 periods.

${ }^{27}$ While we do not have direct observations, we derive the network numbers in 1983 using the network numbers and new entrants in 1984 together with the network exit rate in 1983 (according to our assumption, the banking deregulation started in 1983 so the exit rate $\gamma=0.08)$. Also, we estimate the number of cards per network in 1983 based on the average size of the ATM-only network in 1984.
} 
- Post-shock equilibrium path since 1984: (1) numbers of ATM-only networks and ATM-debit networks each year, (2) number of new entrants each year, (3) network debit adoption rate each year, and (4) the output ratio between an ATM-debit network and an ATM-only network each year.

Table 1. Parameter Values for Model Calibration

\begin{tabular}{lccccc}
\hline \hline Parameters & & Value & Parameters & & Value \\
\hline Cost function & $c_{0}$ & 3 & Demand function & $\omega^{a}$ & 1 \\
& $c_{1}$ & 2 & & $\omega^{d}$ & 1.6 \\
& $g_{0}$ & 0.7 & & $d_{0}$ & 1500 \\
& $g_{1}$ & 0.11 & & $d_{1}$ & 3 \\
Adoption cost & $I_{0}$ & 3.12 & Exogenous exit & $\gamma_{p r e}$ & 0.01 \\
& $I_{1}$ & 0.13 & & $\gamma$ & 0.08 \\
Outside option & $\pi^{\phi}$ & 0.1 & Adoption success & $\lambda$ & 0.07 \\
Sunk cost & $K$ & 10 & Discount factor & $\beta$ & 0.95 \\
\hline
\end{tabular}

Our calibrated model fits the data very well. Basically, we assume that the networks have a quadratic cost function and face elastic industry demands. We also assume that networks have an exogenous annual exit rate of 1 percent in the pre-shock era. This matches the similar low exit rate of commercial banks before the mid-1980s as shown in Figure 2B. With the parameter values we choose, our model calibration matches the preshock steady state in 1983: There were 118 networks in the industry and each network had a half million cards in circulation.

We then introduce the twin shocks. The debit innovation creates a superior product (i.e., $\left.\omega^{d}>\omega^{a}\right)$. It also generates continuing technological progress for ATM-debit networks (i.e., $0<g_{1}<1$ ), but the adoption is random (i.e., with the success rate $\lambda$ ) and becomes increasingly costly over time (i.e., $1>I_{1}>0$ ). At the same time, the banking deregulation introduces a higher exit risk for networks (i.e., $\gamma>\gamma_{\text {pre }}$ ), but it also allows networks to better achieve the technological potentials enabled by the debit innovation (In other words, without the deregulation, ATM-debit networks would have a slower pace of technological progress $\left.g_{1}\right)$. 
5A. Network Numbers

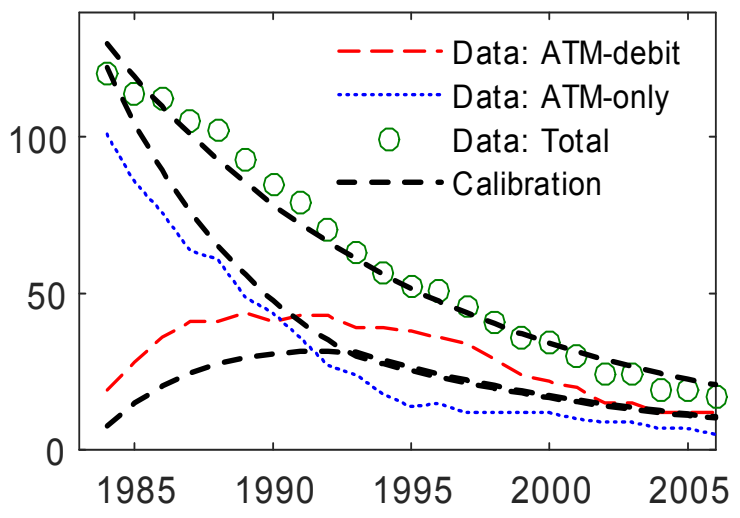

5C. Exit Rates

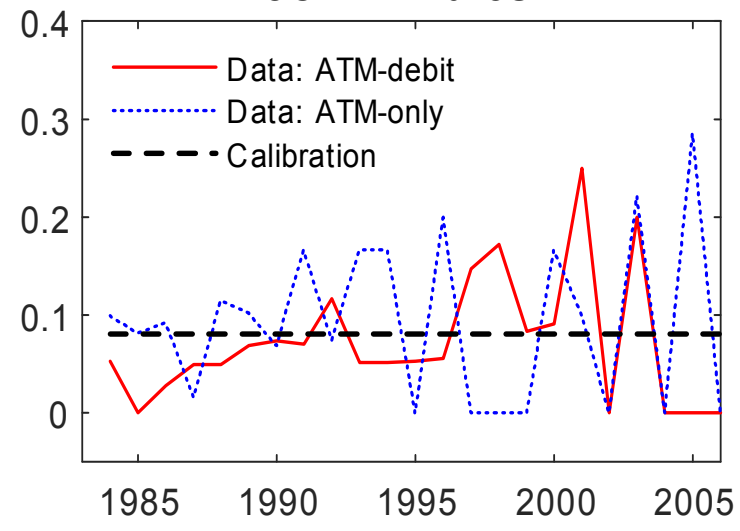

5E. Network Size Ratio

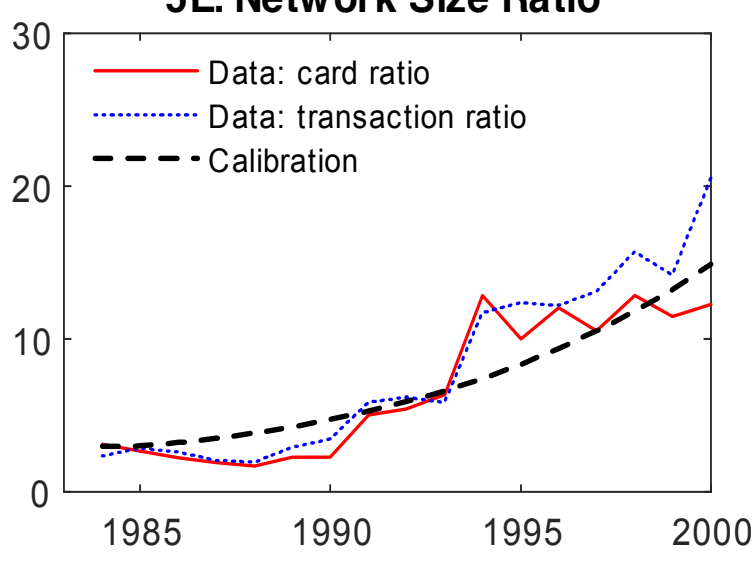

5B. New Entrants

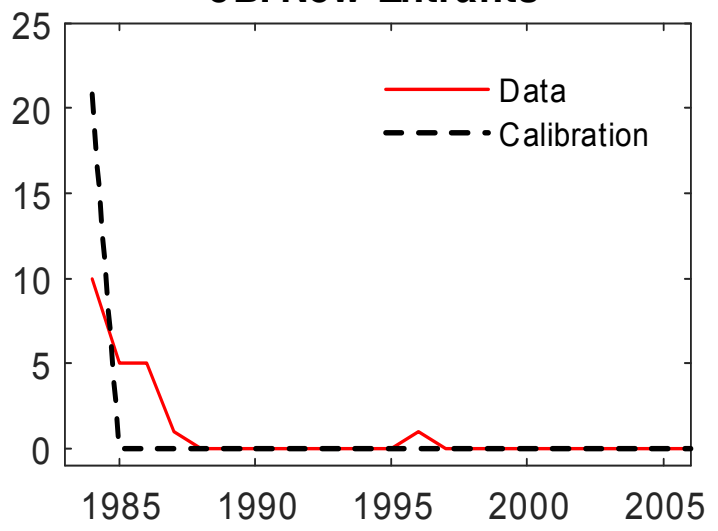

5D. Debit Adoption Rate

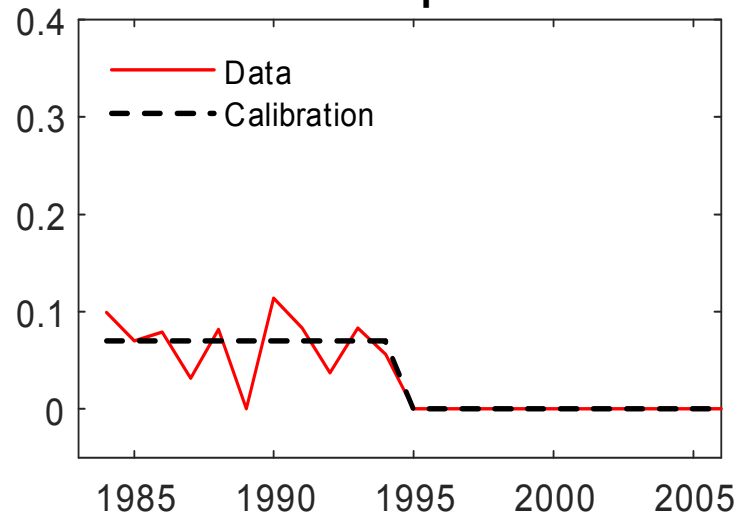

5F. Market Shares of Cards

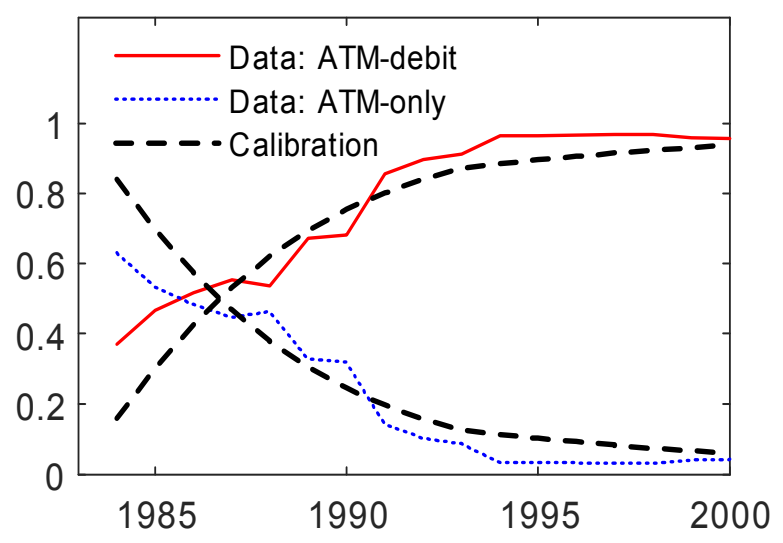

Figure 5: Model Fit — Baseline Calibration 
Figures 5A-5F compare our calibrated results with the data for the post-1984 era, which show a good match.

1. Our model fits well with the total number of networks over time. Also, the calibrated number of ATM-only networks declines monotonically, while the number of ATM-debit networks initially rises before it later falls.

2. A short wave of entry occurs right after the shocks. Specifically, our calibrated model generates 21 new entrants in 1984, which equals the total number of new entrants that occurred between 1984-1987 in the data.

3. The calibrated sample period 1984-2006 falls into the time range $t<T^{\prime \prime}$, so the model has an exogenous network exit rate of 8 percent, which matches the average of the data. ${ }^{28}$

4. Our calibration endogenously determines an 11-year window of debit adoption ending in 1994, the same as the data. The model's annual debit adoption rate before 1994 is 7 percent, which matches the average of the data.

5. Our calibration generates a rising output ratio over time between an ATM-debit network and an ATM-only network. The magnitude is consistent with those in the data measured either by cards in circulation or ATM transaction volumes.

6. The evolution of market shares of different cards generated by our calibration closely matches those of the data.

Our calibrated model also delivers useful results for the untargeted moments, including prices, profits, and value functions. Although we do not have data for those, the calibration results confirm the predictions of our theory in Section III. We show in Figures 6A-6D that along the equilibrium time path, both prices of ATM-only and ATM-debit cards decrease. As a result, the profit of an ATM-only network falls, but the profit of an ATM-debit network rises because technological progress dominates the price decline. Also, the calibration verifies that after the arrival of shocks, the value

\footnotetext{
${ }^{28}$ Our baseline calibration yields $T^{\prime \prime}=T+115$, and all the remaining ATM-only networks exit at $T^{\prime \prime}$.
} 
function of an ATM-debit network increases over time, but that of an ATM-only network decreases. The latter explains why our theory predicts that entry can only occur for one period right after the arrival of the twin shocks.
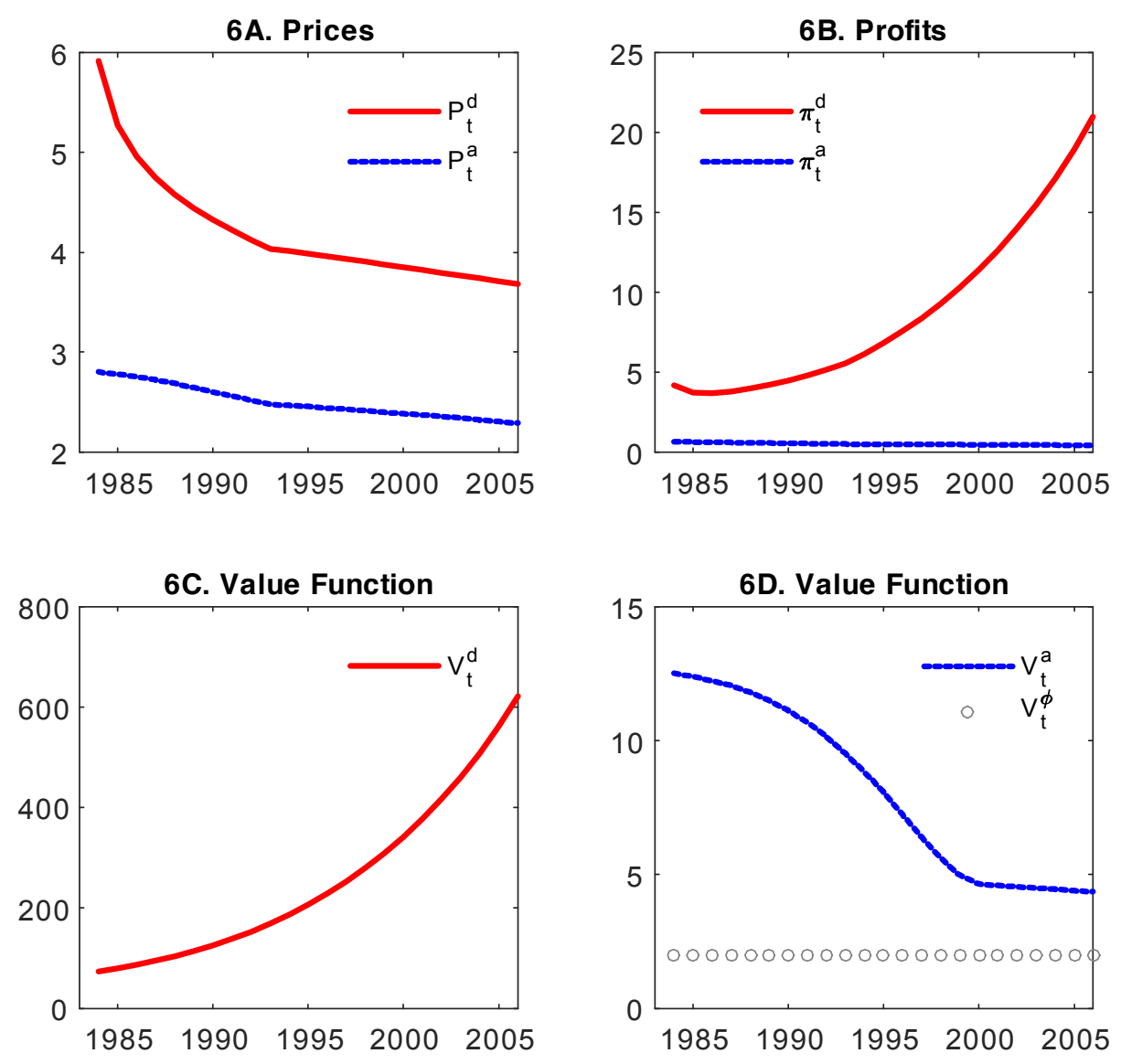

Figure 6. Model Fit — Baseline Calibration (continued)

\section{Counterfactual Analysis}

Our model and baseline calibration incorporate the joint effects of debit innovation and banking deregulation on the evolution of the U.S. ATM and debit card industry. This framework also allows us to evaluate the contribution of each factor by conducting counterfactual simulations, as we will show in this section. 


\section{A. No Debit Innovation}

We first consider the counterfactual experiment where there is banking deregulation but no debit innovation. In this case, the deregulation only causes a higher exogenous exit risk for ATM networks ( $\gamma=0.08$ compared with $\gamma_{\text {pre }}=0.01$ ), but does not introduce the new debit product nor technological progress (recall that unlike ATM-debit networks, ATM-only networks showed little size change during the sample period).
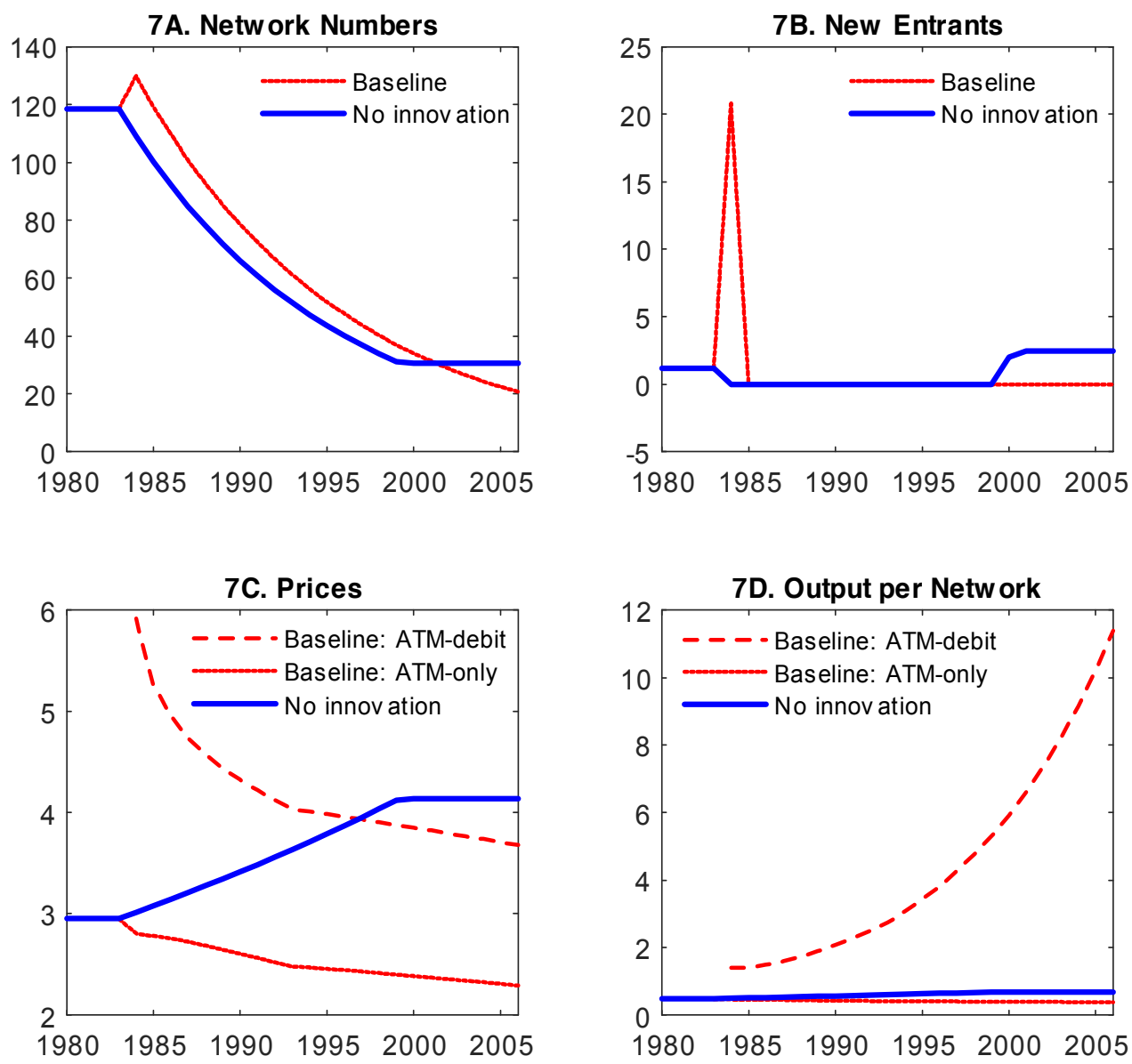

Figure 7. Counterfactual - No Innovation

Figures 7A-7D plot the simulation results and compare them with our baseline calibration. Absent debit innovation, deregulation nevertheless brings down the firm numbers, but the pattern of entry, price, and firm size behave very differently from the data as well as our baseline calibration. This can be explained as follows. 
Given the fixed ATM-only technology but a higher exogenous exit risk, fewer firms can be supported at the new steady state and the price needs to be higher to compensate firms for their elevated exit risk. The higher price of ATM-only cards results in a higher output per firm but a lower industry output, which implies a welfare reduction.

In the simulation, the industry would reach the new steady state in the year 1999 . During the transitional path, the price would be rising because incumbents continue to exit at the exogenous rate $\gamma=0.08$ but no new firm would enter given the price is below the new steady-state level. Entry then starts to occur when the industry eventually approaches the new steady state, and entry and exit balance out each period to keep the firm numbers fixed in the long run.

\section{B. No Deregulation}

We now consider another counterfactual experiment where there is debit innovation but no banking deregulation. In this case, all networks have a low exogenous exit risk $\left(\gamma=\gamma_{\text {pre }}=0.01\right)$, but the technological progress of ATM-debit networks is at a slower pace than the baseline calibration.

For illustration purposes, we first consider a scenario where we set the technological progress rate $g_{1}=0.05$, nearly a half of the value used in the baseline calibration. Figures $8 \mathrm{~A}-8 \mathrm{D}$ present the simulation results.

Compared with the baseline, on the one hand, the absence of deregulation implies a lower exogenous exit risk (i.e., a lower value of $\gamma$ ) that encourages entry; on the other hand, technological progress becomes slower (i.e., a lower value of $g_{1}$ ), which discourages entry. The overall effect then depends on the two opposite effects. In this particular example, the former effect dominates, so the number of entrants is larger than the baseline. Along the equilibrium path, prices are lower for both ATM-debit and ATMonly cards, so deregulation turns out undermining the industry performance. Moreover, because of the larger number of entrants and slower technological progress, networks stop adopting the debit innovation earlier and ATM-debit cards' market share becomes smaller than the baseline. 
8A. Netw ork Num bers

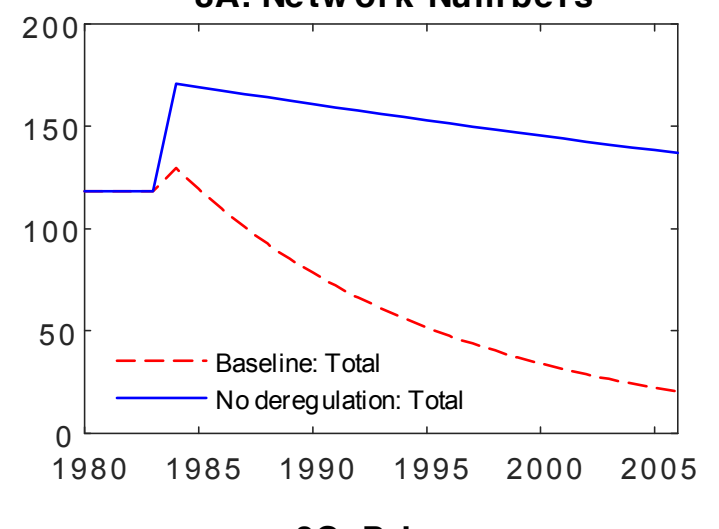

8C. Prices

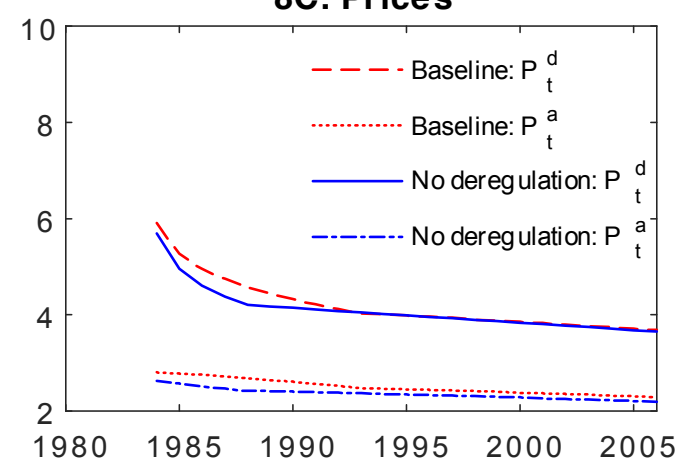

8E Debit Adoption Rate

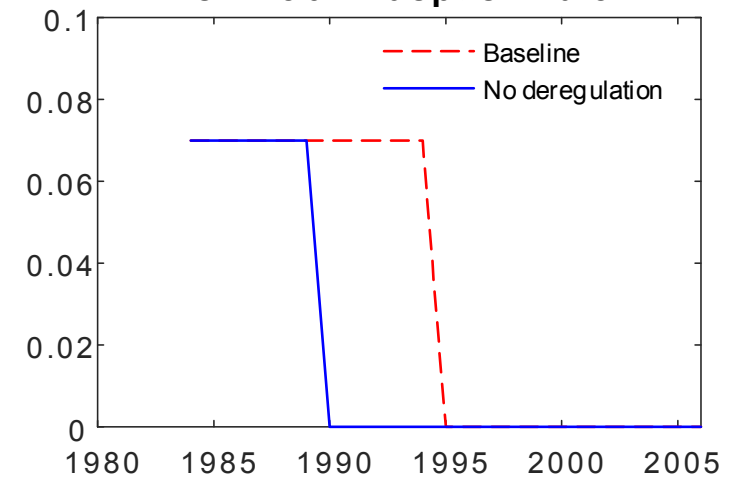

8B. New Entrants

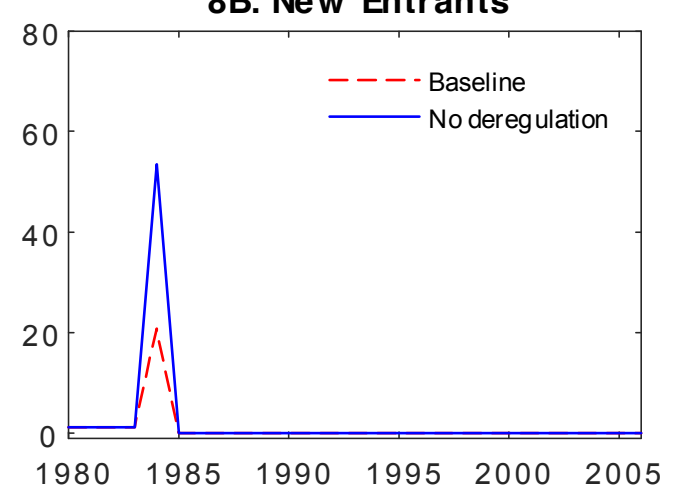

8D. Profits

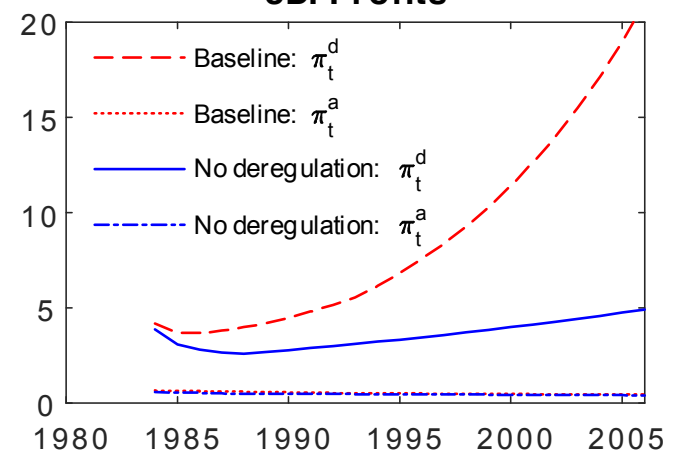

8F. Market Shares of Cards

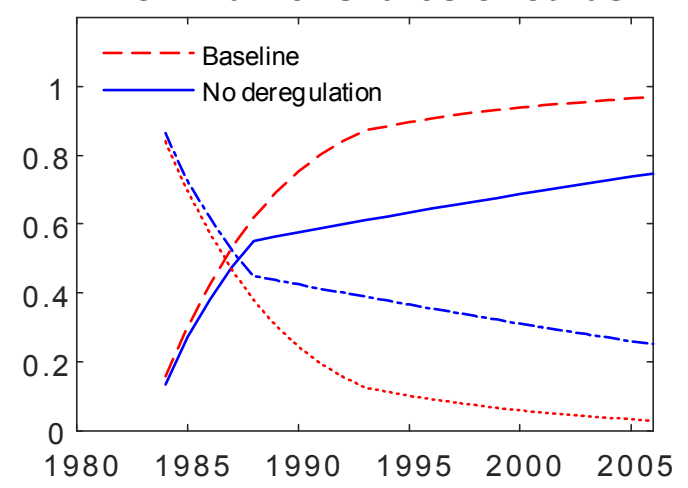

Figure 8. Counterfactual - No Deregulation (Scenario 1)

However, the implication could vary by the post-shock technological progress rate. To show this, we consider another scenario, in which we keep everything else the same as above but set $g_{1}=0.035$, about a third of the value used in the baseline calibration. Figures 9A-9D present the simulation results. 
In this case, the number of entrants is smaller than the baseline and the prices of cards become higher. Therefore, deregulation enhances the industry performance. Also, because of slower technological progress, we find that debit adoption stops earlier and ATM-debit cards' market share becomes smaller than the last counterfactual scenario.

\section{A. Network Num bers}

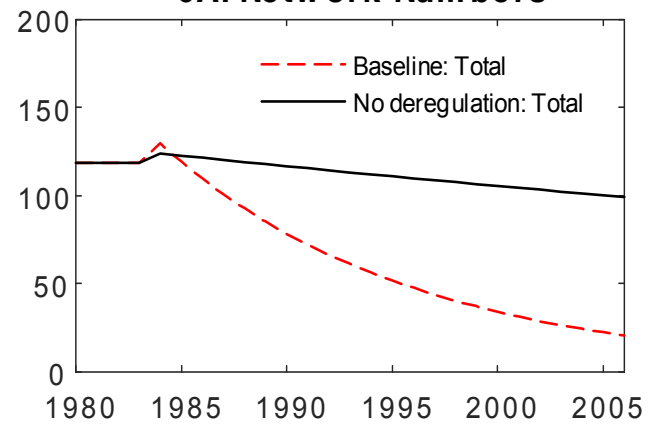

9C. Prices

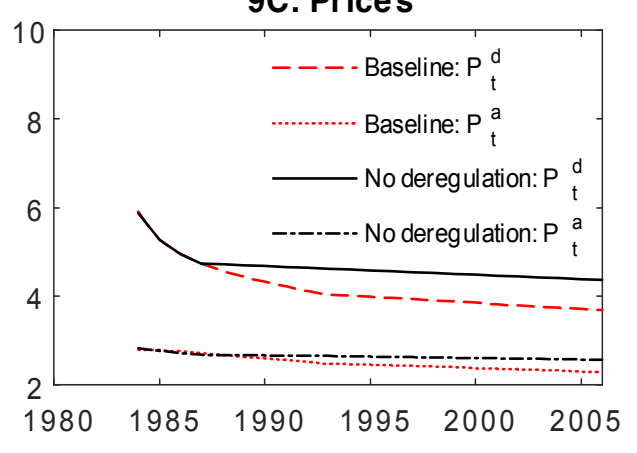

9E. Debit Adoption Rate

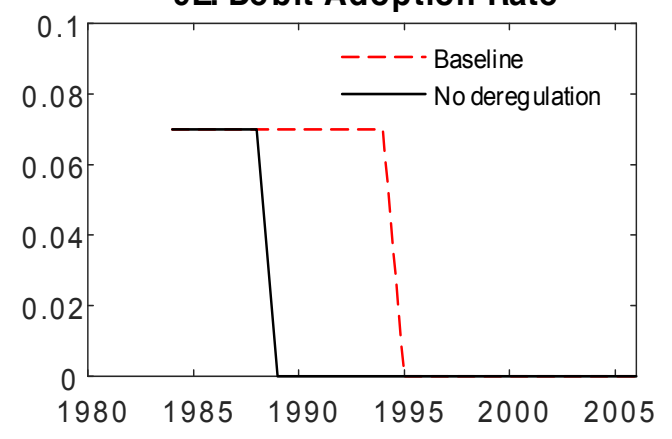

9B. New Entrants

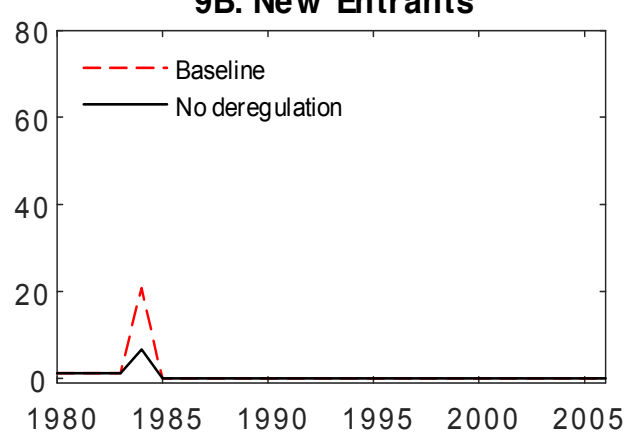

9D. Profits

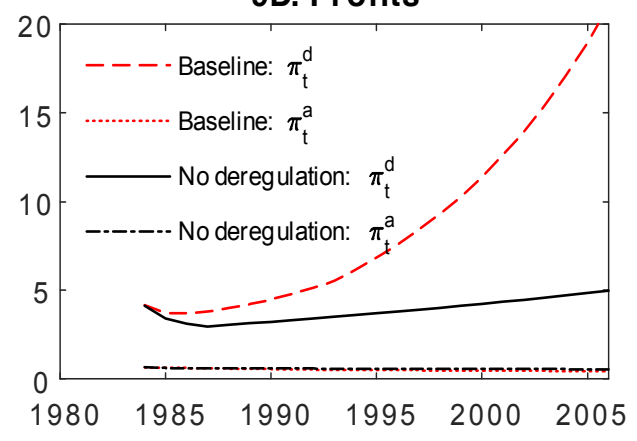

9F. Market Shares of Cards

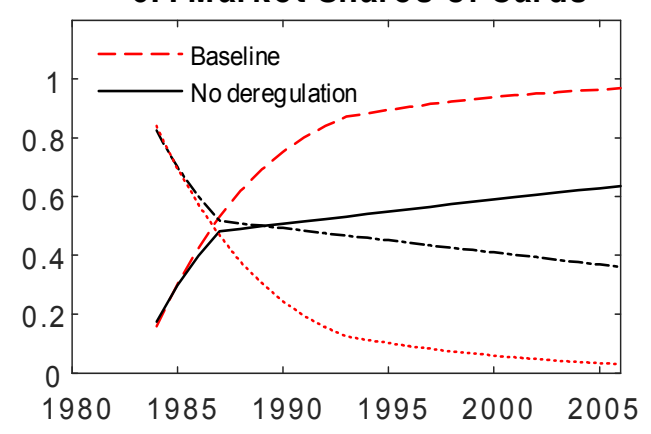

Figure 9. Counterfactual - No Deregulation (Scenario 2) 


\section{Additional Discussions}

\section{A. Anticipated Shocks}

Our model assumes that debit innovation and banking deregulation arrived as unexpected shocks. This is mainly a simplifying assumption given that our data do not provide information to identify whether (or to what extent) the shocks were anticipated. However, it is possible to extend our analysis to incorporate anticipated shocks if data on market expectation become available. Formally, let $\mu$ denote the possibility that the shocks will arrive in any period. We can then rewrite the pre-shock value functions as

$$
\begin{aligned}
U_{t}^{\phi}= & \pi^{\phi}+\max \left\{\beta\left[\mu V_{t+1}^{\phi}+(1-\mu) U_{t+1}^{\phi}\right],\right. \\
& \left.\beta\left[\mu V_{t+1}^{a}+(1-\mu) U_{t+1}^{a}\right]-K\right\}, \\
U_{t}^{a}= & \max \left\{\pi^{\phi}+\beta\left[\mu V_{t+1}^{\phi}+(1-\mu) U_{t+1}^{\phi}\right],\right. \\
& \pi^{a}+\beta \mu\left[\gamma_{p r e} V_{t+1}^{\phi}+\left(1-\gamma_{p r e}\right) V_{t+1}^{a}\right]+ \\
+ & \left.\beta(1-\mu)\left[\gamma_{p r e} U_{t+1}^{\phi}+\left(1-\gamma_{p r e}\right) U_{t+1}^{a}\right]\right\},
\end{aligned}
$$

where $V_{t+1}^{\phi}$ and $V_{t+1}^{a}$ are post-shock value functions defined in Eqs (8) and (9).

Compared with our baseline calibration, the anticipated arrival of the shocks would increase the option value of entering as an ATM-only network. As a result, we would have a larger number of ATM networks and hence a lower price and a higher industry output in the pre-shock equilibrium. This would also lead to lower prices and higher industry outputs than the baseline along the post-shock equilibrium path since incumbents can try the debit adoption one period ahead of the new entrants. Appendix $\mathrm{C}$ provides the technical details for solving the pre-shock equilibrium with anticipated shocks.

\section{B. Firm Heterogeneity}

In our model, firms are assumed identical if they have the same technology. This is a theoretical simplification, but in reality firms could be heterogenous. In fact, before the debit innovation arrived, ATM-only networks did differ in size. Then, a natural question is whether the observed network growth was driven by the debit adoption or 
by something else. For instance, large ATM-only networks may have enjoyed some advantages allowing them to grow faster and then happened to adopt the debit innovation on the wav.
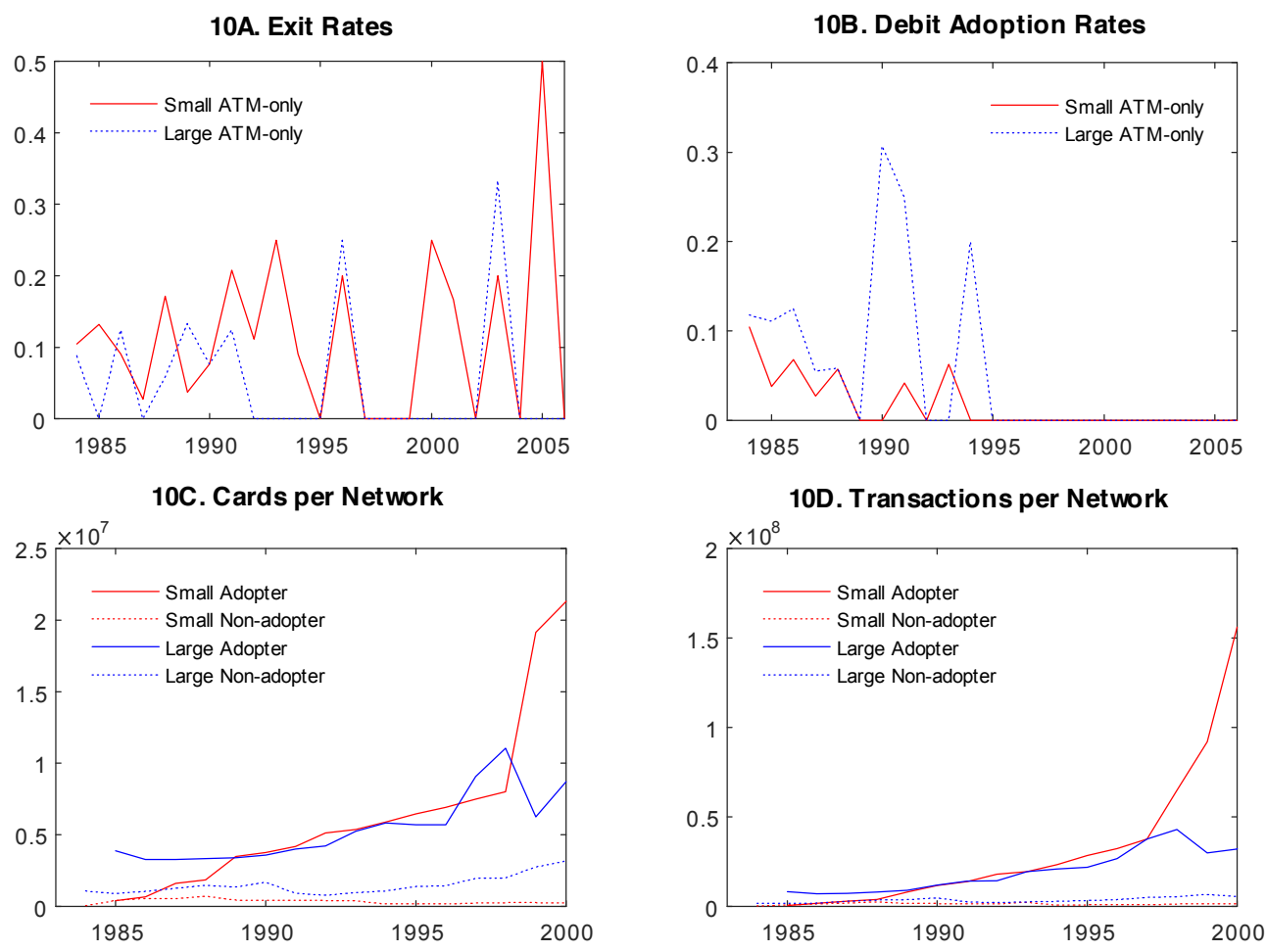

Figure 10. Network Size and Performance

To address this question, we group the ATM-only networks by size in 1984 . We name the networks that ranked in the top one-third in terms of cards in circulation as "large ATM-only networks," and the rest as "small ATM-only networks." We then keep track of their performance over time. Figures 10A-10D report the results.

- Figure 10A shows that "large" and "small" ATM-only networks, as long as they hadn't adopted the debit innovation, had similar exit rates in most time periods.

- Figure 10B shows that "large ATM-only networks" had a higher annual debit adoption rate than the "small" ones.

- Figures 10C-10D show that both "large" and "small" networks enjoyed faster size growth only after they had adopted the debit innovation. Otherwise, they had similar low growth rates. 
These findings are informative. Figure 10B suggests the presence of some firm size advantages: Large networks may perform better in terms of debit adoption. This could be explained by some possible network effects in the sense that large networks were more likely to convince merchants to accept their debit cards due to their large cardholder base and better infrastructure in place.

Figures 10C-D suggest that the debit innovation was indeed the driving force behind network growth. Regardless of initial size differences, networks expanded fast only after they had adopted debit innovation. This helps rule out the possible spurious causality that large networks may have enjoyed some advantages other than the debit innovation that allowed them to grow faster.

It is possible to extend our model to incorporate heterogenous network sizes prior to the shocks. ${ }^{29}$ The extension may allow us to explore more details of the industry evolution, including the possible network effect that lends large ATM-only networks advantages in adopting the debit innovation. However, given that our baseline model has explained the data quite well, the gains of making this extension might be limited compared with the greater complexity added to the analysis.

\section{Concluding Remarks}

The U.S. ATM and debit card industry is an intriguing example of the broader debate on industrial evolution. Unlike many manufacturing industries studied in the literature, this financial service industry experienced both technological innovation and deregulation over its life cycle.

We construct a dynamic equilibrium model to study how a major product innovation (introducing the new debit card function) interacted with banking deregulation drove the industry shakeout. Calibrating the model to a novel dataset on network entry, exit,

\footnotetext{
${ }^{29}$ For instance, we may extend our baseline model by assuming in the pre-debit era, potential entrants can pay either a high fixed cost $K^{l}$ to set up a large ATM-only network or a low fixed cost $K^{s}$ to set up a small ATM-only network. At equilibrium, entrants are indifferent with either option, and large networks charge a higher fee than small networks because they provide a better ATM service. Banks then choose to participate in different networks based on their customers' heterogenous taste for network services $\theta$. The supply equals the demand, which pins down the network numbers by type. After the debit innovation and banking deregulation arrive, as suggested by Figures 10 A-D, we could then allow large ATM-only networks to adopt the debit innovations with a higher success rate than small networks, though both networks are subject to the same higher exogenous exit rate $\gamma$ caused by the deregulation.
} 
size, and product offerings shows that our theory fits the quantitative pattern of the industry well. The model also allows us to conduct counterfactual analyses to evaluate the respective roles that innovation and deregulation played in the industry evolution. We find that absent technological innovation, deregulation may only introduce additional disturbances to the industry. As a result, the number of firms may fall accompanied with an increase in price and a decrease in industry output. On the other hand, absent deregulation, innovation may not generate as fast technological progress as otherwise. Overall, whether deregulation enhances or undermines industry performance depends on how much it facilitates technological progress relative to the additional disturbances it introduces to the industry.

While our study considers the life cycle of a particular financial service industry, the findings and analysis can be generalized. The stylized facts that we document on the evolution of firm numbers, entry, exit, size, and technology adoption provide additional empirical evidence on industry evolution. Also, the structural approach that we use can be readily applied to other industries, and we discuss the possibilities of extending our analysis to incorporate anticipated shocks and firm heterogeneity.

For future research, there might be several directions to pursue. First, one may consider exploring the role that entry cohorts play in the industry evolution. Some studies (e.g., Klepper, 1996; Klepper and Simons, 2000) argue that early entrants may enjoy first-mover advantages in the presence of internal adjustment costs. On the contrary, vintage capital theories (e.g., Jovanovic and Lach, 1989; Mitchell, 2002) suggest that later entrants tend to perform better with newer and better capital. While we did not detect a significant cohort effect in the ATM and debit card industry, it would be interesting to explore this further. ${ }^{30}$ Second, one may study different firm exit modes. In our dataset, about 35 percent of networks exited through merger or acquisition. Presumably, some of those networks may not necessarily have failed, but they might be merged or acquired for other reasons. It would be interesting to investigate those cases provided additional information becomes available. Third, one may consider the effect

\footnotetext{
${ }^{30}$ For example, Agarwal and Gort (1996) and Agarwal, Sarkar, and Echambadi (2002) examine the relationship between firm entry by industry life cycle stage and subsequent performance using data from dozens of industries.
} 
of external adjustment costs on early industry development. Our model implies that an industry quickly reaches the steady state in the pre-shakeout stage, which deviates from the slow buildup of network numbers as we observe in the data. One possible way to address the discrepancy is to consider external adjustment costs in the industry (e.g., Mussa, 1977), for which firms may want to smooth their entry over time. Finally, due to data limitations, our analysis focuses on the binary quality of networks: ATM-only or ATM-debit services. In reality, network differentiation could also have a strong horizontal component because consumers may want to use ATMs close to where they live, work, shop, etc. Provided richer data become available, future studies could incorporate local competition of networks into the analysis. 


\section{Appendix A: Timeline of the Industry Evolution}

$\begin{array}{lcc}\begin{array}{l}\text { Set up ATM } \\ \text { networks }\end{array} & \begin{array}{c}\text { ATM networks } \\ \text { produce }\end{array} & \begin{array}{c}\mathrm{P}=\mathrm{P}^{\mathrm{a} *} ; \mathrm{Q}=\mathrm{D}\left(\mathrm{P}^{\mathrm{a} *}\right) ; \mathrm{q}=\mathrm{q}\left(\mathrm{P}^{\mathrm{a} *}\right) ; \mathrm{N}=\mathrm{N}^{\mathrm{a}} \\ \mathrm{Entry} \text { and exit balance out }\end{array} \\ \mathbf{0} & \mathbf{1} & \mathbf{2} \\ \text { (Industry starts) } & & \end{array}$

$\begin{gathered}\mathrm{N}^{\mathrm{a}} \text { ATM networks upgrade } \\ \mathrm{N}^{\varnothing} \text { new networks enter }\end{gathered}$
$\begin{gathered}\text { Some ATM-debit } \\ \text { networks start producing; } \\ \text { some remain ATM-only }\end{gathered}$

\section{Appendix B: Model Solution}

This appendix provides additional details and the procedure of numerically solving the model. Recall in our model, the exogenous parameters are $\left(\beta, d_{0}, d_{1}, c_{0}, c_{1}, \pi^{\phi}\right.$, $\left.K, \omega^{a}, \omega^{d}, I_{0}, I_{g}, g_{0}, g_{1}, \lambda, \gamma_{p r e}, \gamma\right)$. The endogenous variables are the number of new entrants $N^{\phi}$ at time $T$, the final time of debit adoption $T^{\prime}$, the starting time of voluntary exit $T^{\prime \prime}$, and the sequences of prices $\left(P_{t}^{a}, P_{t}^{d}\right)$, outputs per network $\left(q_{t}^{a}, q_{t}^{d}\right)$, profits $\left(\pi_{t}^{a}\right.$, $\left.\pi_{t}^{d}\right)$, network numbers $\left(n_{t}^{a}, n_{t}^{d}\right)$, value functions $\left(V_{t}^{a}, V_{t}^{d}\right)$, and voluntary exits $x_{t}^{a}$.

As we have characterized in the paper, the dynamics of the prices, outputs per network, profits, network numbers, value functions, and voluntary exits will be determined by the number of new entrants $N^{\phi}$ and the timing of endogenous final adoption and 
voluntary exit $T^{\prime}$ and $T^{\prime \prime}$. Among them, $T^{\prime \prime}\left(>T^{\prime}\right)$ will be determined by the outside option value $\pi^{\phi}$. So we can use the following algorithm to solve for the model solution with two-dimensional grid search over control space of $N^{\phi}$ and $T^{\prime}$, and in the meantime we derive the dynamics of all other endogenous variables.

- Step 1: Define the grid points by discretizing the control space of the numbers of entrants $N^{\phi}$ and the endogenous time $T^{\prime}$. Make an initial guess of the numbers of entrants $N^{\phi}$.

- Step 2: Take $N^{\phi}$ as given, and make a guess of the final adoption time $T^{\prime}$. We can characterize the dynamics of the solution for three time ranges - from $T$ to $T^{\prime}$, from $T^{\prime}$ to $T^{\prime \prime}$, and from $T^{\prime \prime}$ and onward. Given the initial numbers of entrants and the final adoption time, we first obtain the sequences of prices, outputs per network, profits, network numbers, voluntary exits till $T^{\prime}$. As $T^{\prime \prime}>T^{\prime}$, we then derive the voluntary exit time $T^{\prime \prime}$ with the condition that the profits of ATM-only networks equate the outside option value $\pi^{\phi}$. With the known $T^{\prime \prime}$, we then solve the full paths of all other endogenous variables $\left(P_{t}^{a}, P_{t}^{d}, q_{t}^{a}, q_{t}^{d}, \pi_{t}^{a}, \pi_{t}^{d}, n_{t}^{a}, n_{t}^{d}\right.$, $\left.x_{t}^{a}\right)$. Applying the backward induction based on 400 periods, we also derive the sequences of value functions $\left(V_{t}^{a}, V_{t}^{d}\right)$ from equations (8)-(10) given $N^{\phi}$ and $T^{\prime}$.

- Step 3: Given $N^{\phi}$, we now verify whether the guess of time $T^{\prime}$ satisfies the condition $\Psi_{t} \geq 0$ for all $t \leq T^{\prime}$ and $\Psi_{t}<0$ for $t>T^{\prime}$ shown in equation (12). If the condition is not satisfied, we then make another guess of $T^{\prime}$ and repeat Step 2 until we derive the consistent final adoption time $T^{\prime}$ and other variable values for the given $N^{\phi}$.

- Step 4: We then verify whether the guess of the number of entrants $N^{\phi}$ satisfies the condition shown in equation (11). Check the discrepancy of equation (11) given $N^{\phi}$ and the derived $T^{\prime}$ from Step 3. If it is above the desired tolerance (set to $1 e-5)$, go back and repeat Step 2 and 3 until both conditions in equations (11) and (12) are satisfied within the desired tolerance level. Thus, we have solved for the dynamics of all endogenous variables. 


\section{Appendix C: Anticipated Shocks}

This appendix provides details for solving the pre-shock steady-state equilibrium with anticipated shocks.

Under the free entry condition, we can rewrite Eq (23) as

$$
U^{\phi}=\pi^{\phi}+\max \left\{\beta U^{\phi}, \beta\left[\mu V^{a}+(1-\mu) U^{a}\right]-K\right\} .
$$

This implies that

$$
\begin{gathered}
U^{\phi}=\pi^{\phi}+\beta U^{\phi} \Longrightarrow U^{\phi}=\frac{\pi^{\phi}}{1-\beta}, \\
\text { and } U^{\phi}=\pi^{\phi}+\beta\left[\mu V^{a}+(1-\mu) U^{a}\right]-K .
\end{gathered}
$$

Therefore,

$$
\frac{\pi^{\phi}}{1-\beta}=\left[\mu V^{a}+(1-\mu) U^{a}\right]-\frac{K}{\beta} .
$$

Because of the sunk cost paid, an incumbent network would strictly prefer staying in the industry. Hence, we can rewrite Eq (24) as

$$
\begin{aligned}
U^{a}= & \pi^{a}+\beta \mu\left[\gamma_{p r e} V^{\phi}+\left(1-\gamma_{p r e}\right) V^{a}\right]+ \\
& \left.+\beta(1-\mu)\left[\gamma_{p r e} U^{\phi}+\left(1-\gamma_{p r e}\right) U^{a}\right]\right\}
\end{aligned}
$$

which implies

$$
\left[1-\beta(1-\mu)\left(1-\gamma_{p r e}\right)\right] U^{a}=\pi^{a}+\beta \gamma_{p r e} U^{\phi}+\beta \mu\left(1-\gamma_{p r e}\right) V^{a} .
$$

In addition, at the steady state, we have

$$
1-G\left(\frac{P^{a^{*}}}{\omega^{a}}\right)=N^{a} q^{a}\left(P^{a^{*}}\right)
$$

and the network profit $\pi^{a}$ is determined by $P^{a^{*}}\left(N^{a}\right)$. Under our parameterization, this means that

$$
\pi_{t}^{a}\left(P^{a^{*}}\right)=\left(c_{1}-1\right) c_{1}^{\frac{c_{1}}{1-c_{1}}} c_{0}^{\frac{1}{1-c_{1}}}\left(P^{a^{*}}\right)^{\frac{c_{1}}{c_{1-1}}}
$$




$$
d_{0}\left(\frac{P^{a^{*}}}{\omega^{a}}\right)^{-d_{1}}=N^{a}\left(\frac{P^{a^{*}}}{c_{0} c_{1}}\right)^{\frac{1}{c_{1}-1}}
$$

The pre-shock steady-state equilibrium is then pinned down by Eqs (28), (30), (32), and (33). Note that $V^{a}$ is the value function of being an ATM-only network in the period when the shocks indeed arrive and the number of existing networks is $N^{a}$, and $V^{a}\left(N^{a}\right)$ can be numerically solved using the algorithm described in Appendix B above.

\section{REFERENCES}

Agarwal, Rajshree and Michael Gort, (1996). "The Evolution of Markets and Entry, Exit and Survival of Firms," Review of Economics and Statistics, Aug., 489-498.

Agarwal, Rajshree, MB Sarkar and Raj Echambadi, (2002). "The Conditioning Effect of Time on Firm Survival: A Life Cycle Approach," Academy of Management Journal, 45(8), 971-994.

Barbarino, Alessandro, and Boyan Jovanovic, (2007). "Shakeouts and Market Crashes," International Economic Review, 48, 385-420.

Cabral, Luis, (2012). "Technology Uncertainty, Sunk Costs, and Industry Shakeout," Industrial and Corporate Change, 21, 539-552.

Demers, Elizabeth and Baruch Lev, (2001). "A Rude Awakening: Internet Shakeout in 2000," Review of Accounting Studies, 6, 331-359.

Fein, Adam, (1998). "Understanding Evolutionary Process in Non-manufacturing Industries: Empirical Insights from the Shakeout in Pharmaceutical Wholesaling," Journal of Evolutionary Economics, 8, 231-270.

Felgran, Steven D, (1984). "Shared ATM Networks: Market Structure and Public Policy," New England Economic Review, Feb., 23-38. 
Felgran, Steven D, (1985). "From ATM to POS Networks: Branching, Access, and Pricing," New England Economic Review, May-June, 44-61.

Filson, Darren, (2001). "The Nature and Effects of Technological Change over the Industry Life Cycle," Review of Economic Dynamics, 4(2), 460-494.

Filson, Darren, (2002). "Product and Process Innovations in the Life Cycle of an Industry," Journal of Economic Behavior $\&$ Organization, 49 (1), 97-112.

Gort, Michael and Steven Klepper, (1982). "Time Paths in the Diffusion of Product Innovations," The Economic Journal, 92, Sept., 630-653.

Hayashi, Fumiko, Richard Sullivan, and Stuart E. Weiner, (2006). A Guide to the ATM and Debit Card Industry: 2006 Update. Federal Reserve Bank of Kansas City.

Hayashi, Fumiko, Richard Sullivan, and Stuart E. Weiner, (2003). A Guide to the ATM and Debit Card Industry. Federal Reserve Bank of Kansas City.

Hopenhayn, Hugo (1994). "The Shakeout," University of Rochester Working Paper.

Jayaratne, Jith, and Philip Strahan, (1997). "The Benefits of Branching Deregulation," Federal Reserve Bank of New York Economic Policy Review, Dec., 13-29.

Jovanovic, Boyan and Saul Lach, (1989). "Entry, Exit, and Diffusion with Learning by Doing," American Economic Review, 79 (4), 690-699.

Jovanovic, Boyan and Glenn M. MacDonald, (1994). "The Life Cycle of a Competitive Industry," Journal of Political Economy, 102(2), 322-347.

Klepper, Steven, (1996). "Entry, Exit, Growth, and Innovation over the Product Life Cycle," American Economic Review, 86, June, 562-583.

Klepper, Steven and Elizabeth Graddy, (1990). "The Evolution of New Industries and the Determinants of Market Structure," Rand Journal of Economics, 21, 27-44.

Klepper, Steven and Kenneth Simons, (2000). "The Making of an Oligopoly: Firm Survival and Technological Change in the Evolution of the U.S. Tire Industry," Journal of Political Economy, 108(4), 728-758. 
Klepper, Steven and Kenneth Simons, (2005). "Industry Shakeouts and Technological Change," International Journal of Industrial Organization, 23, 23-43.

Koeva, Petya, (2000). "The Facts About Time-to-Build," The IMF Working Paper No. $00 / 138$.

McAndrews, James J., (2003). "Automated Teller Machine Network Pricing - A Review of the Literature," Review of Network Economics, 2(2), 146-158.

Mitchell, Matthew, (2002). "Technological Change and the Scale of Production," Review of Economic Dynamics 5(2), 477-488.

Mussa, Michael, (1977). "External and Internal Adjustment Costs and the Theory of Aggregate and Firm Investment," Economica, New Series, 44 (174), 163-178.

Tibbals, Elizabeth, (1985). "NOTE: ATM Networks Under the McFadden Act: Independent Bankers Association of New York v. Marine Midland Bank, N.A." American University Law Review, 35, 271-300.

Utterback, James, Fernando Suarez, (1993). "Innovation, Competition, and Industry Structure," Research Policy, (22), 1-21.

Wang, Zhu, (2008). "Income Distribution, Market Size and the Evolution of Industry," Review of Economic Dynamics, 11(3), 542-565.

Winston, Clifford, (1998). "U.S. Industry Adjustment to Economic Deregulation," Journal of Economic Perspectives, 12, 89-110. 